\title{
Centrifuge Tests to Assess Seismic Site Response of Partially Saturated Sand Layers
}

\author{
Morteza Mirshekari \\ Majid Ghayoomi, Corresponding Author
}

\begin{abstract}
Seismic response of unsaturated soil layers may differ from that of saturated or dry soil deposits. A set of centrifuge experiments was conducted to study the influence of partial saturation on seismic response of sand layers under scaled Northridge earthquake motion. Steady state infiltration was implemented to control and provide uniform degrees of saturation profiles in depth. The amplification of peak ground acceleration at the soil surface was inversely proportional to the degree of saturation, especially in low period range. The cumulative intensity amplification of the motion was also higher in unsaturated soils with higher suctions. The lateral deformation and surface settlement of partially saturated sand with higher stiffness were generally lower than that in dry soil. Although neglecting the effect of partial saturation in sand layers might be conservative with respect to seismic deformations, it may result in underestimating the surface design spectra.
\end{abstract}

Keywords: Seismic Site Response, Unsaturated Soils, Centrifuge Modeling 


\section{INTRODUCTION}

Seismic waves generated by earthquakes often travel through soils with different mechanical and hydraulic characteristics where they can be dramatically altered in terms of intensity, frequency content, and duration. This transition is commonly evaluated using "Site Response Analysis", which is a crucial step toward seismic design of soil-structure systems. Applications of site response analysis include development of design response spectra for surface structures, estimating seismically induced stresses, strains, and settlements, and liquefaction hazard assessment. Local site conditions such as soil density, plasticity index, stiffness, and damping can significantly affect seismic site response [1-8]. Thus, ignoring the effects of changes in the site conditions may lead to inaccurate assessment of the site response.

The role of local site condition and the intensity of rock motion in the site response have been highlighted using fully monitored and instrumented sites during past earthquakes [1, 4-15]. In general, lower site amplification factors were observed during earthquakes with higher bedrock motion intensities [8, 11-15]. This could be attributed to the nonlinear stress-strain behavior of soils and higher damping values as a result of higher induced strain levels. The site amplification was, also, found inversely proportional to the square root of shear wave velocity as a representative measure of local site conditions $[1,4-7,16]$. Data obtained from instrumented sites under strong ground motions (e.g. $[17,18])$ as well as physical modeling experiments (e.g. [19, 20]) can be used to develop guidelines for site response assessment. Traditionally, different 
methods have been employed to consider the effects of local site conditions and motion intensity in the surface motion evaluation, ranging from simplified procedures regulated by seismic provisions [21-23] to more complex site-specific ground response analysis for sensitive seismic designs using available software [24-29]. In current seismic provisions the local site condition is reflected through site classification system using an average shear wave velocity of the top $30 \mathrm{~m}$ of the soil profile () (Table 1).

Degree of water saturation is among the parameters that influence the seismic response of soil layers [30]. Inter-particle suction in partially saturated soils increases the effective stresses on the grain skeleton [31]. This, in turn, yields to different soil dynamic properties including small-strain and strain-dependent shear modulus and damping [32-43]. As a result, seismic wave propagation mechanisms may vary in partially saturated soil layers [44] that would lead to a different seismic site response [30, 45-49]. Soils in either dry or fully saturated conditions have been believed to result in more conservative solutions because matric suction in unsaturated soils increases the ground stiffness. Therefore, partial saturation has not been directly considered in the state-of-the-practice site response analysis. However, recent investigations on the site response in unsaturated soils showed that this assumption might not be always reasonable [47-49]. Further, the influence of the degree of saturation on seismic response analysis is often considered by incorporating the in-situ measured shear wave velocity of shallow unsaturated soil layers. However, the extent of this influence might be beyond the suction-dependency of the dynamic soil properties where the wave propagation mechanisms may vary [45]. In addition, soil properties may differ between the time of the construction and prior to the earthquake due to the seasonal fluctuation 
of water table. Thus, recognizing this difference would be essential in assessing the uncertainty in projected site response.

Yang [45] analytically studied the frequency-dependent amplification of inclined vertically propagated shear waves (SV waves) in soil layers overlying bedrock. The results indicated that a slight decrease in the degree of saturation of fully-saturated soil layers causes a dramatic difference in vertical amplification of the SV waves. Specifically, for regular earthquake frequencies, unsaturated soils may lead to a higher vertical amplification than saturated soil layers. D'Onza et al. [46] implemented the small-strain modulus and damping obtained from suction-controlled resonant column tests in a series of numerical site response analyses. Suction was found to significantly affect the natural frequency and Peak Ground Acceleration (PGA) amplification factor in clayey silt and silty sand layers. According to their numerical study, the natural frequency of the soil layers increased in higher suction values whereas PGA amplification factor was reduced. Ghayoomi et al. [30] studied seismically induced settlements in partially saturated sand by applying sinusoidal cyclic loads to sand layers in a set of suctioncontrolled centrifuge tests using steady-state infiltration technique [50]. The least amount of surface settlement occurred in middle range degrees of saturation due to the increase in shear modulus. Moreover, they observed a maximum 20\% increase in PGA amplification factor in unsaturated sand with respect to the one in dry condition [47].

Recently, Ghayoomi and Mirshekari [48] and Mirshekari and Ghayoomi [49] numerically studied the seismic response of partially saturated sand and silt layers 
using site response software DeepSoil [24]. In the absence of any available numerical procedure to account for partial saturation, this influence was investigated by adjusting the soil unit weight and effective stress for any given degree of saturation. Changes of the effective stress in unsaturated soils, in turn, altered soil dynamic properties including small-strain and straindependent shear modulus and damping. Accordingly, partial saturation in the soil layers appeared to considerably influence the site response, where the extent of this effect was a function of soil type as well as induced motion characteristics. For example, partial saturation in sandy soils with low range suction level (e.g. $10 \mathrm{kPa}$ ) resulted in higher amplifications and lateral deformations whereas in silty soils with high suction range (e.g. $70 \mathrm{kPa}$ ) led to lower amplifications and lateral deformations in comparisons with those of dry soil layers.

Despite the proven influence of the degree of saturation on the dynamic soil properties and the site response, well-documented field or laboratory seismic site response data in partially saturated soils are still needed. Centrifuge physical modeling of free-field seismic ground response using a "degree of saturation-controlled" system is of a great value to validate this effect and to calibrate future numerical and analytical predictive models. This paper describes the adaptation and modification of an experimental setup to control the degree of saturation in a geotechnical centrifuge and its application to study seismic site response of partially-saturated soil layers. Furthermore, the effect of partial saturation on the site response of a sand layer is investigated and discussed in terms of different motion characteristics including PGA amplification factor $\left(F_{P G A}\right)$, low-period and mid-period amplification factors $\left(F_{a}\right.$ and $F_{v}$, 
respectively), 5\% damped spectral acceleration, Arias intensity $\left(I_{a}\right)$, lateral deformation, and seismically induced settlements.

\section{SUCTION CONTROL IN GEOTECHNICAL CENTRIFUGE}

Modeling unsaturated soils under high gravitational acceleration is a challenging task where controlling suction or the degree of saturation is the key to any systematic investigation involving partially saturated soils. Centrifuge modeling of unsaturated fine-grained soils could be accomplished by using methods such as compacting soils with a target degree of saturation [51] or in-flight free drainage of an initially saturated specimen [52]. For sand layers, however, centrifugation along with free drainage leads

to very low degrees of saturation due to their relatively higher permeability values. To address this problem, steady state infiltration was implemented in this study to generate uniform degree of saturation profiles inside in-flight centrifuge. This approach was devised from centrifuge permeameters [53-55], mainly used to streamline measurements of hydraulic parameters in unsaturated soils. Recently, similar steady state infiltration method was successfully incorporated in a laminar container inside a large arm centrifuge to study seismically induced settlements in partially saturated sand layers [50].

Dell'Avanzi et al. [56] analytically solved Richard's equation of water flow in unsaturated soils [57] for steady state infiltration, under higher gravitational field inside a geotechnical centrifuge. The suction profile along the depth of the specimen during steady state infiltration can be estimated using the following equations [56]: 
where:

$a$ is the Gardner's hydraulic conductivity parameter in $\mathrm{kPa}^{-1}$ [58], $e$ is the natural base of logarithms, $v_{m}$ is the discharge velocity in $\mathrm{m} / \mathrm{s}, Z_{m}$ is height of any location in the specimen from its bottom in $\mathrm{m}, N_{r}$ is the g-level depending on $z_{m}$ parameter, $k_{\text {sat }}$ is soil hydraulic conductivity in saturated condition, $\psi_{0}$ is suction at the bottom of the specimen defining the boundary conditions, and $\rho_{w}$ is the density of water in $\mathrm{kg} / \mathrm{m}^{3}$. Then, the degree of saturation profiles could be obtained using hydraulic constitutive models relating the degree of saturation and matric suction; Soil Water Retention Curves (SWRC) (e.g. van Genuchten [59]). Applying steady state infiltration in higher g-levels results in a uniform suction with height with small transition zones. For example, profiles of the degree of saturation are illustrated in Figure 1 (a) and (b) for different discharge velocities and g-levels, respectively, during the centrifugation of a $22.86 \mathrm{~cm}$ of model Ottawa sand.

Dell'Avanzi et al. [56], also, determined suction scaling factor for steady state flow condition where a prototype infiltration is to be represented by a model with the length and discharge velocity scaling factors of $1 / N$ and $N$, respectively. Comparison of prototype and model infiltration equations led to a suction scaling factor of unity for relatively uniform acceleration fields (i.e. ratio of centrifuge arm's length to the length of specimen is greater than 10). For the case of smaller centrifuges, however, the suction scaling factor becomes slightly different leaning toward lower values within the upper portion of the profile (this is observed in the analytical solutions in Figure 1(b)). This 
scaling factor is solely for an infiltration problem, where the same prototype suction profile would be achieved in a model (in large centrifuges) undergoing a N-times increased discharge velocity. This concept, however, should not be considered when mechanical behavior of soils is studied. When suction stresses that were measured in the model should be projected to prototype values, matric suction in the centrifuge has to be scaled using the conventional pressure scaling factor (i.e. $N_{\sigma}=1$ ). However, in this study matric suction was indirectly obtained from the measured degrees of saturation, so the interchangeable application of soil water retention in model and prototype was carefully considered. Since SWRC is not a function of g-level $[60,61]$ measured degrees of saturation in centrifuge experiments can be linked to matric suction using 1-g SWRC.

\section{EXPERIMENTAL PROGRAM}

\subsection{Experimental Setup}

\subsubsection{Centrifuge, Shaking Table, and Container}

The recently renovated $5 \mathrm{~g}$-ton centrifuge at the University of New Hampshire was used in this investigation [62]. The arm radius is $1 \mathrm{~m}$ from the center of rotation to the platform in its fully extended position. The centrifuge is equipped with an in-flight shaking table that is capable of imposing harmonic or seismic displacement time histories. A hydraulic servo valve controlled by National Instruments system operates the table. Due to servo valve limitations, the current system has an analog displacement threshold of $10-\mathrm{mm}$. Four fluid supply lines, two devoted to the hydraulic fluid and two to the infiltrating water, were passed through the centrifuge slip ring. A 
laminar container was used herein to avoid adverse boundary effects on the shear wave propagation [63]. The container consists of 19 rectangular aluminum laminates, each $12.7 \mathrm{~mm}$ thick, which are separated using cylindrical bearing with negligible frictional resistance [64]. The inner dimensions of the box are $35.5 \mathrm{~cm}$ in length, 17.7 $\mathrm{cm}$ in width, and $25.4 \mathrm{~cm}$ in height with the ratio of length to width as 2. A schematic of the container is shown in Figure 2. In order to allow for free drainage of water, the container base plate was replaced with an outflow control aluminum plate with a network of 14 drainage ports.

\subsubsection{Infiltration Setup}

The basic procedure to apply steady-state infiltration inside the laminar container in this study is similar to Ghayoomi et al. [50]. Inflow water was supplied from an 80gallons pressurized tank located outside the centrifuge. An inlet slip-ring port was deployed to route the water to 8 fog-spray nozzles. Three sets of BETE nozzles were utilized in this investigation to obtain various discharge rate and, therefore, different degree of saturation profiles. 1/8 PJ10, 1/8 PJ20, and 1/8 PJ40 nozzles were used for degrees of saturation lower than $45 \%$, between $45 \%$ and $60 \%$, and higher than $60 \%$, respectively. In order to control the inflow rate a solenoid valve was employed in conjunction with an ultra-precision needle valve ahead of the nozzles. The solenoid valve was used to open the water flow during the centrifugation while the needle valve was in charge of controlling the inflow rate. Drainage was conducted through four of the outflow ports opened by miniature solenoid valves. The outflow water was guided 
to four drainage tanks mounted on the front, back, and bottom of centrifuge platform (Figure 2).

\subsubsection{Instrumentation}

Instrumentation setup comprises of dielectric sensors, accelerometers, and LVDTs to measure volumetric water content, acceleration, and displacement, respectively. Four EC-5 dielectric sensors from Decagon Devices were placed at different depths (i.e. $1.6,6.3,12.4$, and $18.1 \mathrm{~cm}$ in model scale from the top of the soil surface). Several PCB Piezoelectronics accelerometers were used to record acceleration time histories along the depth of the specimen (i.e. at surface, bottom and depths of 5.7, 11.4, and $17.1 \mathrm{~cm}$ in model scale from the top of the specimen as shown in Figure 2). Two accelerometers were placed apart from each other at some levels to ensure the uniformity of motion across the container. In addition, one accelerometer was mounted to the base plate of the container to measure the actual applied motion. Two MHR 500 LVDTs and three MHR250 LVDTs were mounted on the top and side of the specimen to measure the vertical and lateral deformations, respectively.

\subsection{Material}

F-75 Ottawa sand was used in this study as it is fine-enough to hold suctions up to 10 $\mathrm{kPa}$ and yet permeable-enough to permit the steady-state infiltration. The grain size distribution of the sand is illustrated in Figure 3 (a). Sand was dry-pluviated in the container to reach the target void ratio of 0.66 . Soil Water Retention Curve (SWRC) of this sand measured by Mirshekari and Ghayoomi [49] and Le and Ghayoomi [43] are shown in Figure 3 (b) alongside fitted curves for both drying and wetting paths using 
van Genuchten's equation [59]. Geotechnical physical and hydraulic properties of the sand are summarized in Table 2. The Hydraulic Conductivity Function (HCF) fitting parameter $\left(\mathrm{a}_{\mathrm{G}}\right)$ necessary for steady state infiltration solution was found to be $2.5 \mathrm{kPa}^{-1}$ using van Genuchten-Mualem model [59].

\subsection{Testing Procedures}

\subsubsection{Sample Preparation}

Loose specimens were prepared inside the laminar container while a plastic membrane was glued to the base plate in order to prevent leakage of sand and water from the gaps between laminates. In addition, a gravel layer was placed at the bottom of the sand specimen to provide a saturated boundary condition, separated from the sand layer using geotextile filters. The final specimen height was $22.86 \mathrm{~cm}$ in model scale with an approximate relative density of $45 \%$. Accelerometers and dielectric sensors were placed at different depths of the soil layer when needed (Figure 2). Upon completing the pluviation, spray nozzles and vertical LVDTs were mounted on the sensor racks atop the container sitting on the in-flight shaking table. Moreover, horizontal LVDTs were placed on a side frame measuring the displacements of the laminates. The specimen was, then, saturated (for saturated and unsaturated tests) by passing de-aired water through two drainage ports on the base plate. A completely prepared and mounted specimen is shown in Figure 4. A slight negligible change in the relative density was measured due to the saturation and centrifugation.

The centrifuge was spun up to 50-g acceleration measured at the middle of the soil layer. Upon reaching the target g-level, the inflow and outflow solenoid valves were 
opened to generate a steady-state infiltration within the specimen. Different discharge rates were obtained in this study by varying the types of nozzles and opening of the needle valve (i.e. $v_{m} / k_{\text {sat }}$ between $1.5 \times 10^{-4}$ to $2.4 \times 10^{-3}$ ). Consequently, various uniform degree of saturation profiles were obtained ranging from 32\% to $68 \%$ (corresponding to matric suctions from 3.9 to $4.9 \mathrm{kPa}$ ) within a short time span after starting the infiltration (e.g. about 1 minute for all the specimens). Some of the achieved degrees of saturation and their corresponding discharge velocities are shown in Figure 5 along with the corresponding analytical solutions (Equation 1). Although a somewhat uniform degree of saturation profile was reached across the height of the specimen, the bottommost section (about $5 \%$ in length) still had a transient degree of saturation varying from the fully saturated boundary condition to the target degree of saturation. This length was aimed to become minimal by increasing the g-level (Figure $1 \mathrm{~b}$ ). The transition zone has to be considered when interpreting and applying the results of this study. After a constant degree of saturation was achieved throughout the specimen, the scaled earthquake motion was applied to the sand layer and the response was captured. Conventionally, a more viscous pore fluid with similar mechanical properties with water has been implemented to address the time scaling conflicts between dynamic and diffusion problems in the centrifuge [65]. However, the mechanisms of dynamic suction variations mainly rely on distortions of water menisci during seismic events and differ from those of excess pore water pressure generation and dissipation. The unsaturated tests in this study were performed in degrees of water saturation much lower than one (for fully saturated) to avoid the time scaling conflict for dynamic problems in the centrifuge models. In addition, the steady state infiltration technique leverages the 
accelerated flow of the water in the soil in high g-level, which would not be the case for higher viscosity fluids.

\subsubsection{Input Earthquake Motion}

Northridge earthquake motion, 1994, captured at WPI station was selected as the desired motion in this investigation, as it encompasses a wide range of frequency contents. The acceleration time history of the original recorded motion was scaled down to meet the shaking table limits (i.e. PGA was scaled from $0.42 \mathrm{~g}$ to $0.3 \mathrm{~g}$ in prototype scale). The frequencies higher than $8 \mathrm{~Hz}$ in prototype scale were filtered from this "desired" motion to obtain the "target" motion for this investigation. As a common practice, in-flight shaking tables are calibrated for a specific earthquake motion by matching the target and the "achieved" motion on the shaking table $[66,67]$. The method introduced by Mason et al. [67] was used through which the "command" motion sent to the shaking table was modified using a set of frequency response analysis, so the achieved motion becomes approximately similar to the target motion. Different characteristics of the final achieved motion in terms of acceleration time history, Arias intensity, Fourier amplitude, and 5\% damped spectral acceleration are

illustrated in Figure 6. Although the same motion was imposed to all the specimens with different degrees of saturation, the input motions recorded at the bottom accelerometer were slightly different. This could be due to the different specimen weights and nonlinear shaking table performance.

\section{RESULTS AND DISCUSSION}


The centrifuge experiments were performed on three dry specimens (D1, D2, and D3), eleven unsaturated specimens (specified with the letter $U$ followed by the degree of saturation) with degrees of saturation varying between $32 \%$ and $68 \%$, and one saturated (S) specimen. The captured acceleration and displacement time histories were post-processed to obtain various motion characteristics. Then, the influence of the degree of saturation on the seismic response was investigated in terms of different motion parameters including PGA, frequency-dependent motion amplification, cumulative intensity amplification, lateral deformation, and seismic settlement. The following results are all presented in prototype scale unless specified.

\subsection{Peak Ground Acceleration Amplification}

PGA amplification factor ( $\left.F_{P G A}\right)$ was calculated at different depths using the following equation:

where PGA and PGA base are the maximum accelerations at a given depth and at the bottom of the specimen (considered as bedrock motion herein), respectively.

As previously mentioned, PGA base slightly varied among different tests that, in turn, influenced the FPGA values. In order to eliminate this effect, a relationship was formulated to normalize all the base motions to a reference one. To find such a correlation, FPGA values were graphed over PGA base for tests with approximately similar degrees of saturation; e.g. D1, D2, and D3 and U48, U49, and U50; shown in Figure 7. 
Knowing the expected trend from previous studies [8, 11-15], FPGA was set inversely proportional to PGAbase for the given limited range of acceleration. The following linear correlation was developed where the slope of the line was similar for dry and partially saturated cases:

where the parameter $d$ indicates the influence of degree of saturation. The FPGA values were modified by moving along the same slope such that a reference base PGA of 0.3 $g$ was achieved for all the tests based on the abovementioned linear relationship:

This modification could increase or decrease the FPGA depending on the values of PGA base (e.g. for the test U66 with PGA base of 0.2828 the FPGA was modified from 1.212 to 1.1131). Modified surface $F_{P G A}$ values for different degrees of saturation are shown in Figure 8 (a). While the amplification factors for dry tests were approximately one, the unsaturated soil condition led to higher amplification factors at surface especially at lower degrees of saturation (with an average increase of 16\%). The amplification factor for the case of fully saturated sand layer was expectedly lower than the ones in dry and unsaturated sand layers due to the de-amplification of motion in possibly fully- or partially-liquefied ground (the liquefaction occurrence was not assured due to the absence of pore water pressure transducers). Therefore, the focus of this paper has been mainly on comparing the response of dry and unsaturated sand layers.

Amplification factor at the soil surface was shown to be inversely proportional to the degree of saturation with a nonlinear pattern. The amplification factor is somewhat 
constant for mid-level degrees of saturation where the change in suction is almost negligible (i.e. between $45 \%$ and $70 \%$ degrees of saturation). In addition, the codebased $[21,22]$ amplification factor is demonstrated in Figure $8(a)$ where the weightedaverage shear wave velocity,, was calculated using the following formula:

where $H$ is the soil layer thickness, $z$ is the depth, and $v_{s}$ is the depth-dependent shear wave velocity resulted from small-strain shear modulus values at each depth. The site class, thereafter, was estimated using Table 1 where regardless of the choice of the small-strain modulus formula (i.e. [40, 68, and 69]), a Class D was assigned. Also, estimating an average shear wave velocity for 30-m soil layer as suggested by the code or for $11.43-\mathrm{m}$ soil layer in this study would yield to the same site class. Although partial saturation increased the PGA amplification, the code-suggested FPGA value for this case is conservatively higher than nearly all the experimental values. The values suggested by seismic provisions were developed based upon a large number of recorded data from the past earthquakes in different site conditions [70] while this study limited the testing conditions (e.g. uniform degree of saturation profiles; one type of sand, and one earthquake motion) to evaluate the effect of partial saturation.

The observed higher amplification in unsaturated sand layer in comparison with the one in the dry condition is consistent with the ones from simplified numerical site response analysis [48, 49] and centrifuge physical modeling under cyclic loads with equivalent PGA of $0.55 \mathrm{~g}$ and $0.65 \mathrm{~g}$ [47]. However, Ghayoomi and McCartney [47] found the code-based amplification factors to be lower than the measured FPGA values. 
This difference could be either a result of simulating seismic motions using cyclic loads in Ghayoomi and McCartney [47] or different suction-dependent site response mechanisms in very strong ground motions such as continuous full cycles of dynamic loads.

Parameters influencing the site response could be simplistically explored by inspecting the analytical solution to a linear Single Degree of Freedom (SDOF) system under cyclic motion. This SDOF system could represent a uniform soil layer overlying bedrock. The maximum acceleration amplification ratio in such a system would be approximated as follows [71]:

where:

$\beta_{S}$ is the soil damping ratio and $I$ is the rock/soil impedance ratio equal to $\gamma_{r} V_{r} / \gamma_{s} V_{s}$, in which $\nu_{r}$ and $\nu_{s}$ are the unit weights and $V_{r}$ and $V_{s}$ are the shear wave velocities of the rock and soil, respectively. As the ratio of $\gamma_{r} / \gamma_{s}$ is between 1.1 and 1.4 for majority of sites [70], the amplification ratio becomes a function of the shear wave velocity and damping where both are influenced by motion intensity and local site conditions. However, for sands, the shear wave velocity is mainly a function of local site conditions while the damping is predominantly affected by the motion intensity [70]. Despite the useful insights gained from the analytical solution to the dynamic response of the SDOF system, this simplified equation might not be used in real applications where soil becomes nonlinear under relatively intense earthquakes especially in layered grounds; e.g. Northridge region during the 1994 earthquake [72]. Equation 6, however, might be 
used to shed light on different aspects of the effect of partial saturation on site response where both parameters affecting the SDOF response (i.e. shear wave velocity and damping) vary by changes of the degree of saturation. Shear wave velocity or small-strain shear modulus are increased in partially saturated soils as a function of matric suction [38, 40, and 73]. On the contrary, damping decreases while matric suction increases [41]. Given the inversely proportional relations between the amplification factor and both shear modulus and damping in Equation 6, the increase in shear wave velocity of unsaturated soils yields to lower amplification whereas the decrease in damping leads to higher amplification. As a result, the influence of partial saturation on the site response should be holistically explored considering the interaction between the change in shear modulus and damping.

Shear modulus and damping are functions of their small-strain values and induced level of strain in soils. Small-strain shear modulus is proportional to the square root of effective stress in dry or saturated soils [68, 69] while small-strain damping is correlated to the effective stress raised to a much lower power (e.g. -0.08 according to Menq [74]). Therefore, the influence of the effective stress is more pronounced on shear wave velocity in comparison with damping, resulting in a general trend of lower amplification factors for stiffer sites [21]. The presence of suction in unsaturated soils increases the effective stress, however, the variations of small-strain dynamic properties for different degrees of saturation might not only depend on the effective stress [73]. Dong et al. [73] discussed that water can soften the soil matrix in unsaturated soils by reducing the inter-particle friction that contradicts the added stiffness caused by the matric suction. Hence, the influence of damping and shear 
modulus on the site response may become comparable. Also, the extent of the influence of partial saturation on the site response could vary in depth depending on the dominance of variations in either damping or shear modulus. Adding a constant suction stress to the soil profile (as performed in this study), the ratio of the change in damping over the change in shear modulus would rise in surficial ground and, as a result, amplification factor may become higher for unsaturated soils than that in dry condition at the ground surface.

Further, the seismically induced strain level in soil layers plays an important role in interpreting the acceleration amplification factors. Basically, higher intensity earthquake motion leads to higher strain-dependent damping and lower strain-dependent shear modulus. Then, the amplification factor decreases $[11,12]$ as a result of the interaction of these two parameters. In unsaturated soil conditions, however, the induced shear strains are affected not only by the intensity of the motion but also by the soil stiffening and lower damping. Depending on the induced level of shear strain, the mobilized shear modulus and damping in soil layers may vary and, consequently, alter the amplification factor.

Since matric suction increases the contact effective stresses in unsaturated soils, more insights might be gained by illustrating FPGA versus matric suction, shown in Figure 8 (b). In addition, Lu et al. [75] discussed that it is the combined effect of the matric suction and the degree of saturation that influence the behavior of unsaturated soils. They synthesized experimental data from shear or tensile strength tests and proposed "suction stress" parameter that could be practically responsible for the mechanical behavior of unsaturated soils; as follows: 
where:

$\sigma^{s}$ is the suction stress, $u_{a}$ and $u_{w}$ are pore air and pore water pressures, respectively, and $\mathrm{a}$ and $\mathrm{n}$ are parameters for the van Genuchten [59] SWRC model. FPGA values are shown versus suction stress in Figure 8 (c). Although the performed tests cover a wide range of degree of saturation, only a slight variation occurred in terms of matric suction (i.e. from 3.9 to $4.9 \mathrm{kPa}$ ) while the suction stress expands the range from 0.8 to $2.3 \mathrm{kPa}$. The suction stress might be a better predictor of seismic soil behavior while the amplification factor was not coherently linked to the change in matric suction. Overall, unsaturated specimens showed a higher amplification factor at surface, however, FPGA decreases as suction stress increases.

In order to understand the variations of amplification factor along the depth, FPGA profiles are shown over the height of the sand layer for different degrees of saturation in Figure 9 (only for the tests with five accelerometers in the middle array); where an average $F_{P G A}$ is presented for the tests with similar degrees of saturation. The degree of saturation imposed a depth-dependent influence on PGA amplification factor. Despite the observed trend at the soil surface, shown in Figure 8, FPGA values in depth of unsaturated sand layers are mostly (except for the lowest degree of saturation) lower than the ones of dry sand. This difference can be associated with the coupled effects of depth-, strain-, and suction-dependent damping and shear modulus on motion amplification pattern. For example, the suction stress results in a higher increase in the effective stress in shallow soils where total stresses are low. Further, the inconsistent 
amplification profiles in unsaturated soil layers would imply more complex wave propagation mechanisms in unsaturated soils [45].

\subsection{Frequency-dependent Motion Amplification}

Surface to bedrock amplification of response spectra or Fourier spectra could be used to investigate the frequency-dependent amplification of seismic motions. Low-period and mid-period amplification factors are commonly evaluated as average values of Ratio of Response Spectra (RRS) or the ratio of Fourier spectra within a period or frequency range; e.g. between 0.1 to 0.5 s and between 0.4 to $2 s$ for $F_{a}$ and $F_{v}$ for the recorded data of Loma Prieta earthquake 1989, respectively [5]. An average value of RRS between 0.1 to $0.5 \mathrm{~s}$ and 0.6 to $2 \mathrm{~s}$ were used herein to calculate $F_{a}$ and $F_{v}$, respectively, since for the specific case of this study the values of RRS at $0.4 \mathrm{~s}$ do not represent amplification at mid-term periods; as shown in Figure 10. $F_{a}$ and $F_{v}$ variations for different degrees of saturation and suction stresses are shown in Figure 11. Both amplification factors were significantly higher at soil surface in partially saturated specimens than the ones in dry condition. This clarifies that unsaturated condition yields to higher amplification at surface regardless of the period range. An average increase of $19 \%$ and $6 \%$ were observed in $F_{a}$ and $F_{v}$ values of unsaturated specimens than dry ones, respectively. This indicates a more significant influence of unsaturated condition on motion amplification at low-period range. Since no strong correlation between the $F_{a}$ and $F_{v}$ and $P G A_{\text {base }}$ was found for the tests with similar degree of saturation, the frequency-dependent amplification factors were not modified with respect to the base motion. This explains the reason that the data was more scattered 
in terms of $F_{a}$ and $F_{v}$ in comparison with the $F_{P G A}$. In order to better compare the response of dry and unsaturated sand layers in terms of frequency-dependent amplification, 5\% damped smoothed surface-to-base RRS graphs for selected tests are shown in Figure 12. The general higher motion amplification in unsaturated soil, more substantial in low period range, is discernable.

\subsection{Cumulative Intensity Amplification}

Arias intensity [76], a well-known cumulative intensity characteristic, was selected to represent the accumulated energy buildup during a shaking event in sites with different degrees of saturation. Ratio of the maximum Arias intensity at the soil surface over the maximum Arias intensity at the base was used to quantify the change in energy level of the motions. The variation of Arias Intensity ratio with the degree of saturation is shown in Figure 13, enabling a comparison between the response of dry and unsaturated sand layers. To avoid misinterpretation of the results only the tests with bedrock Arias intensity within a $\pm 5 \%$ offset from the reference dry motion were shown. The presented results show an overall 6\% increase in Arias Intensity amplification for unsaturated specimens where the acceleration was amplified differently in different frequency ranges.

\subsection{Lateral Deformation}

Lateral deformations were obtained using direct measurements of the side LVDTs as well as double integration of acceleration time histories followed by baseline correction of the obtained displacement time histories [77]. Maximum lateral deformation profiles of selected tests based on accelerometer and LVDT measurements are shown in 
Figure $14(\mathrm{a})$ and 14 (b), respectively. Maximum lateral deformation at the soil surface measured by both methods are illustrated against degree of saturation in Figure 14 (c). Overall, the lateral deformation of unsaturated soils obtained from both LVDTs and accelerometers are lower than that of dry soils by the ratio of $10 \%$ and $8 \%$ for LVDT and accelerometer measurements, respectively. This can be attributed to the higher shear modulus and stiffness in unsaturated sand resulted in lower induced shear strain and lateral deformations. The acceleration-based lateral deformation values were lower than those of LVDT measurements that could be due to the double integration process that involved base line correction. This difference in deformations obtained from the two methods is consistent with previous work by Hashash et al. [20].

\subsection{Seismic Settlement}

Seismically induced surface settlements were estimated by an average value of the middle and side LVDT's measurements after shaking and shown in Figure 15. Seismic settlements were generally lower for partially saturated sand layers as a result of stiffer response of unsaturated sand. A minimum settlement at a middle range degree of saturation, e.g. at about 38\% in this case, is consistent with Ghayoomi et al. [30] for seismically induced settlements under cyclic loads. Ghayoomi et al. [30] attributed this trend to the collective effects of seismic compression and post shaking consolidation.

\section{SUMMARY AND CONCLUSION}

The implementation process of a steady state infiltration system in a laminar container inside a geotechnical centrifuge was presented in this paper, which was successfully deployed to control degree of saturation and, consequently, matric suction in scaled 
physical models. Seismic excitation simulating scaled Northridge earthquake motion was applied to $11.43 \mathrm{~m}$-thick dry, saturated, and unsaturated specimens of loose Ottawa sand with uniform degrees of saturation in depth. The recorded data were used to assess the seismic site response under different water saturation profiles.

The effect of partial saturation on PGA amplification factor was shown to be a function of depth as well as the degree of saturation. Despite the commonly-practiced assumption that neglects the seismic response of unsaturated soil layers in order to be conservative, a higher PGA amplification at soil surface was observed as a result of partial saturation with an average increase of $16 \%$. Amplification factors at soil surface decreased as the degree of saturation increased (i.e. lower matric suction and higher suction stress) where it became somewhat constant between the degrees of saturation of $45 \%$ and $70 \%$. Suction stress correlated properly with the amplification factor, demonstrating a potentially promising parameter in evaluating the seismic behavior of unsaturated soils. The PGA amplification factors proposed by seismic provisions were conservatively higher than the ones for the applied range of the degree of saturation in this study with limited soil and motion conditions.

The spectral acceleration in both low- and mid-period ranges were more amplified at soil surface as a consequence of partial saturation showing a more substantial change in the low-period amplification factor. The accumulated energy was intensified within the unsaturated soil layers indicated by a $6 \%$ increase in the surface to bedrock Arias intensity ratio. Despite higher intensity amplification in unsaturated soils, their lateral deformations were generally lower than the dry specimens with an average of $10 \%$ reduction. Seismically induced settlement reduced in unsaturated sand layers 
comparing with the dry ones, with a minimum settlement at a degree of saturation about 38\% due to the higher stiffness.

Albeit unsaturated soils are stiffer than those of dry or saturated where it resulted in lower lateral deformation and surface settlement, partial saturation may trigger more intensity amplification as a result of interaction between different soil characteristics such as shear modulus, damping, and mobilized shear strain within the soil layers. The novel testing procedures and findings of this study highlighted the significance of the degree of saturation in the seismic site response. Further, in order to capture different aspects of this effect, more comprehensive investigation on seismic behavior of variety of soil types in unsaturated state under a wide suite of earthquake motions is needed along with developing numerical procedures to account for partial saturation.

\section{ACKNOWLEDGMENT}

The authors would acknowledge funding of this project by the National Science Foundation through the NSF CMMI grant No. 1333810.

\section{REFERENCES}

[1] Joyner, W., Warrick, R., and Fumal, T., The Effect of Quaternary Alluvium on Strong Ground Motion in the Coyote Lake, California, Earthquake of 1979. Bull. Seism. Soc. Am., 1981, Vol. 71, No. 1, 1333-1349.

[2] Vucetic, M. and Dobry, R., Effect of Soil Plasticity on Cyclic Response. ASCE Journal of Geotechnical Engineering, 1991, Vol 117, No. 1, 89-107.

[3] Vucetic, M., Soil Properties and Seismic Response. Earthquake Engineering, Tenth World Conference, Balkema, Rotterdam, 1992, 1199-1204.

[4] Borcherdt, R. D., Simplified Site Classes and Empirical Amplification Factors for Site-dependent Code Provisions. Proceedings of the 1992 NCEER/SEAOC/BSSC 
Workshops on Site Response During Earthquakes and Seismic Code Provisions, G. R. Martin, ed., University of Southern California, Los Angeles, 1994a.

[5] Borcherdt, R. D., Estimates of Site-dependent Response Spectra for Design (Methodology and Justification). Earthquake Spectra 10, 1994b, 617-653.

[6] Borcherdt, R. D. and Glassmoyer, G., Influences of Local Geology on Strong and Weak Ground Motions in the San Francisco Bay Region, California, and their Implications for Site-Specific Code Provisions. The Loma Prieta Earthquake of October 17, 1989- Strong Ground Motion, R. D. Borcherdt, Ed. U.S. Geological Survey Professional Paper, 1994, 1151-A, A77-A108.

[7] Midorikawa, S., Matsuoka, M., and Sakugawa, K., Site Effects on Strong-motion Records Observed during the 1987 Chiba-Ken-Toho-Oki, Japan Earthquake. Proceedings of the 9th Japan Earthq. Eng. Symp., 1994, 3, E085-E090.

[8] Choi, Y. and Stewart, J.P., Nonlinear site amplification as function of $30 \mathrm{~m}$ shear wave velocity. Earthquake Spectra, 2005, 21 (1), 1-30.

[9] Seed, H. B., Murarka, R., Lysmer, J., and Idriss, I. M., Relationships between Maximum Acceleration, Maximum Velocity, Distance from Source and Local Site Conditions for Moderately Strong Earthquakes. Bull. Seism. Soc. Am., 1976a, 66, 1323-1342.

[10] Seed, H. B., Ugas, C., and Lysmer, J., Site Dependent Spectra for Earthquakeresistant Design. Bull. Seism. Soc. Am., 1976b, 66, 221-244.

[11] Idriss, I. M., Response of Soft Soil Sites during Earthquakes. Proceedings of the Symposium to Honor Professor H. B. Seed, Berkeley, May 1990, 273-289.

[12] Idriss, I. M., Earthquake Ground Motions at Soft Soil Sites. Proceedings of the Second International Conference on Recent Advances in Geotechnical Earthquake Engineering and Soil Dynamics, St. Louis, MO, III, 1991, 2265-2273.

[13] Stewart, J.P., Liu, A.H., and Choi, Y., Amplification Factors for Spectral Acceleration in Tectonically Active Regions. Bull. Seism. Soc. Am., 2003, 93 (1), 332-352.

[14] Silva, W., Darragh, R., Gregor, N., Martin, G., Abrahamson, N., and Kircher, C., Reassessment of site coefficients and near-fault factors for building code provisions. USGS NEHRP program report 98-HQ-GR-1010, 2000.

[15] Borcherdt, R. D., Empirical evidence for site coefficients in building-code provisions. Earthquake Spectra, 2002, 18, 189-218.

[16] Boore, D. M., Joyner, W. B., and Fumal T. E., Estimation of Response Spectra and Peak Accelerations from Western NorthAmerican Earthquakes: An Interim Report, Part 2. U.S. Geological Survey Open-File Report. 1994, 94-127, 40 pp. 
[17] Stewart, J. P., and Kwok, A. O., Nonlinear seismic ground response analysis: Code usage protocols and verification against vertical array data. Proc., Geotechnical Engineering and Soil Dynamics IV, D. Zeng, M. T. Manzari, and D. R. Hiltunen, eds., ASCE Geotechnical Special Publication No. 181, ASCE, Reston, VA, 2008, 1-24.

[18] Kaklamanos, J., Baise, L. G., Thompson, E. M., and Dorfmann, L., Comparison of 1D Linear, Equivalent-linear, and Nonlinear Site Response Models at Six KiK-net Validation Sites. Soil Dynamics and Earthquake Engineering, 2015, 69, 207-219.

[19] Afacan, K. B., Brandenberg, S. J., and Stewart, J. P., Centrifuge modeling studies of site response in soft clay over wide strain range. J. Geotech. \& Geoenvir. Eng., ASCE, 2014, 140 (2), 04013003.

[20] Hashash, Y. M. A., Dashti, S., Romero, M. I., Ghayoomi, M., and Musgrove, M., Evaluation of 1-D Seismic Site Response Modeling of Sand using Centrifuge Experiments. Soil Dyn. Earthquake Eng., 2015, 78, 19-31.

[21] Federal Emergency Management Agency, FEMA, NEHRP Recommended Seismic Provisions for New Buildings and Other Structures. FEMA P-750, 2009.

[22] American Society of Civil Engineers, ASCE., Minimum Design Loads for Buildings and Other Structures. ASCE/SEI 7-10, 2010.

[23] International Code Council., 2012 international building code. Country Club Hills, III: ICC. 2011.

[24] Hashash, Y.M.A., Musgrove, M.I., Harmon, J.A., Groholski, D.R., Phillips, C.A., and Park, D., DEEPSOIL 6.1, User Manual. Urbana, IL, Board of Trustees of University of Illinois at Urbana-Champaign, 2016.

[25] Idriss, I. M. \& Sun, J.I., User's Manual for SHAKE91. Center for Geotechnical Modeling, Dept. of Civil and Environmental Engineering, University of California, Davis, 1992.

[26] Lee, 1K. W. and W. D. L. Finn., DESRA-2: dynamic effective stress response analysis of soil deposit with energy transmitting boundary including assessment of liquefaction potential. Soil Mechanics Series, University of British Columbia, Vancouver, Canada, 1978.

[27] Matasovic, N., Seismic Response of Composite Horizontally-Layered Soil Deposits. Ph.D. Thesis, University of California, Los Angeles, CA, 1993.

[28] Itasca Consulting Group., FLAC, Fast Langrangian Analysis of Continua, Version 5.0. Itasca Consulting Group, Minneapolis, Minnesota, 2005.

[29] Mazzoni, S., F. McKenna, M. H. Scott and G. L. Fenves., The OpenSees Command Language Manual. Pacific Earthquake Engineering Research (PEER) Center: p. 451. Berkeley, California, 2006. 
[30] Ghayoomi, M., McCartney, J.S., \& Ko, H.-Y., Empirical methodology to estimate seismically induced settlement of partially saturated sand. ASCE Journal of Geotechnical and Geoenvironmental Engineering, 2013, 139(3), 1-10.

[31] Lu, N., and Likos, W. J., Suction stress characteristic curve for unsaturated soils. J. Geotech. Geoenviron. Eng., 2006, 1322, 131-142.

[32] Wu, S., Gray, D.H., and Richart Jr., F.E., Capillary effects on dynamic modulus of sands and silts. ASCE Journal of Geotechnical Engineering, 1984, 110(9), 1188-1203.

[33] Qian, X., Gray, D.H., \& Woods, R.D., Resonant column tests on partially saturated sands. Geotechnical Testing Journal., 1991, Vol. 14, No.3, 266-275.

[34] Marinho, E.A.M., Chandler, R.J., \& Crilly, M.S., Stiffness measurements on a partially saturated high plasticity clay using bender elements. In Proc. of the 1 st Intl. Conf. on Unsaturated Soils, Paris, France, 6-8 September. A.A. Balkema, Rotterdam, the Netherlands, 1995, Vol. 2. 535-539.

[35] Mancuso, C., Vassallo, R., and d'Onofrio. A., Small strain behavior of a silty sand in controlled-suction resonant column - torsional shear tests. Canadian Geotechnical Journal, 2002, Vol. 39, No. 1, 22-31.

[36] Mendoza, C. E., Colmenares, J. E., and Merchan, V. E., Stiffness of an unsaturated compacted clayey soil at very small strains. Advanced Experimental Unsaturated Soil Mechanics, Taylor \& Francis Group, London, 2005.

[37] Ng, C.W.W., Xu, J. and Yung, S.Y., Effects of imbibition-drainage and stress ratio on anisotropic stiffness of an unsaturated soil at very small strains. Canadian Geotechnical Journal, 2009, Vol. 46, No. 9, 1062-1076.

[38] Khosravi, A., Ghayoomi, M., and McCartney, J.S., Impact of effective stress on the dynamic shear modulus of unsaturated sand. GeoFlorida 2010, West Palm Beach, Florida, USA. Feb. 20-24. CD-ROM.

[39] Biglari, M., Jafari, M.K., Shafiee, A., Mancuso, C., and d'Onofrio, A., Shear Modulus and Damping Ratio of Unsaturated Kaolin Measured by New SuctionControlled Cyclic Triaxial Device. ASTM Geotechnical Testing Journal, 2011, 34 (5), 1-12.

[40] Ghayoomi, M. and McCartney, J.S., Measurement of small-strain shear moduli of partially saturated sand during infiltration in a geotechnical centrifuge. Special Issue on Advances in Experimental Characterization of Unsaturated Soils, Volume 1. ASTM Geotechnical Testing Journal, 2011, 34(5), 10 pg.

[41] Hoyos, L.R., Suescun-Florez, E.A., and Puppala, A.J., Stiffness of Intermediate Unsaturated Soil from Simultaneous Suction-Controlled Resonant Column and bender Element Testing. Engineering Geology, 2015,188, 10-28. 
[42] Ghayoomi, M., Suprunenko, G., and Mirshekari, M. "Cyclic Triaxial Test to Measure Strain-Dependent Shear Modulus of Unsaturated Sand", Submitted to ASCE International Journal of Geomechanics

[43] Le, K. and Ghayoomi, M. Cyclic direct simple shear test to measure straindependent dynamic properties of unsaturated sand. Submitted to ASTM Geotechnical Testing Journal.

[44] Yang, J. and Sato, T., Effects of Pore-Water Saturation on Seismic Reflection and Transmission from a Boundary of Porous Soils. Bulletin of the Seismological Society of America, 2000, 90 (5), 1313-1317.

[45] Yang, J., Frequency-Dependent Amplification of Unsaturated Surface Soil Layer. ASCE Journal of Geotechnical and Geoenvironmental Engineering, 2006, 132(4), 526-531.

[46] D'Onza, F., d'Onofrio, A., and Mancuso, C., Effects of unsaturated soil state on the local seismic response of soil deposits. Proc. 1st European Conf. on Unsaturated Soils, Durham, UK, 2008; 531- 536.

[47] Ghayoomi,M. and McCartney, J.S., Centrifuge Evaluation of the Impact of Partial Saturation on the Amplification of Peak Ground Acceleration in Soil Layers. Proceedings of GeoCongress 2012 (GSP 225). R.D. Hryciw, A. AthanasopoulosZekkos, and N. Yesiller, eds. ASCE. pp. 1968-1977.

[48] Ghayoomi, M. and Mirshekari, M., Equivalent Linear Site Response Analysis of Partially Saturated Sand Layers. UNSAT2014 conference, Sydney, Australia, 1-6.

[49] Mirshekari, M. and Ghayoomi, M., Simplified Equivalent Linear and Nonlinear Site Response Analysis of Partially Saturated Soil Layers. IFCEE 2015, Geotechnical Special Publication 256, M. Iskander, M.T. Suleiman, J.B. Anderson, D.F. Laefer eds., San Antonio, Texas, 2131-2140.

[50] Ghayoomi, M., McCartney, J.S., and Ko, H.-Y., Centrifuge test to assess the seismic compression of partially saturated sand layers. ASTM Geotechnical Testing Journal, 2011, 34(4).321-331.

[51] Deshpande, S and Muraleetharan, K. K., Dynamic Behavior of Unsaturated Soil Embankments. Proceedings (Geotechnical Special Publication No. 75), Specialty Conference, Geotechnical Earthquake Engineering and Soil Dynamics III, GeoInstitute, ASCE, Seattle, WA, 1998, pp. 890-901.

[52] Ng C. W. W., Leung A. K., Kamchoom V., Garg A., A Novel Root System for Simulating Transpiration-induced Soil Suction in Centrifuge. Geotechnical Testing Journal, 2014, 37(5): 1-15. 
[53] Nimmo, J. R., Rubin, J., Hammermeister, D. P., Unsaturated Flow in a Centrifugal Field: Measurement of Hydraulic Conductivity and Testing of Darcy's Law. Water Resources Research, 1987, 23 (1): 124-134.

[54] Conca, J. L. and Wright, J., Diffusion Coefficients in Gravel under Unsaturated Conditions. Water Resources Research, 1990, 26 (5): 1055-1066.

[55] Dell'Avanzi, E., Unsaturated Flow under Increased Gravitational Field. Ph.D. dissertation, University of Colorado, Department of Civil Environmental and Architectural Engineering, Boulder, CO, 2004.

[56] Dell'Avanzi, E., Zornberg, J. G., and Cabral, A. R., Suction Profiles and Scale Factors for Unsaturated Flow under Increased Gravitational Field. Soils Found., 2004 Vol. 44(3), pp. 79-90.

[57] Richards, L.A., Capillary Conduction of Liquids through Porous Mediums. Physics, 1931, Vol. 1, No. 5, 318-333.

[58] Gardner, W., Some Steady State Solutions of the Unsaturated Water Flow Equation with Applications to Evaporation from a Water Table. Soil Sci., 1958, Vol. 85, pp. 228232.

[59] van Genuchten, M., A Closed Form Equation for Predicting the Hydraulic Conductivity of Unsaturated Soils. Soil Sci. Soc. Am. J., 1980, Vol. 58, pp. 647-652.

[60] McCartney, J. S. and Zornberg, J. G., Centrifuge Permeameter for Unsaturated Soils. II: Measurement of the Hydraulic Characteristics of an Unsaturated Clay. ASCE Journal of Geotechnical and Geoenvironmental Engineering, 2010, 136(8), 1064-1076.

[61] Reis, R. M., Sterck, W. N., Ribeiro, A. B., Dell'Avanzi, E., Saboya, F., Tibana, S., Marciano, C. R., and Sobrinho, R. R., Determination of the Soil-Water Retention Curve and the Hydraulic Conductivity Function Using a Small Centrifuge. ASTM Geotechnical Testing Journal, 2011, 34(5). 1-10.

[62] Ghayoomi, M. and Wadsworth, S., Renovation and Reoperation of a Geotechnical Centrifuge at the University of New Hampshire. 8th International Conference on Physical Modelling in Geotechnics, Gaudin \& White, eds., Perth, CRC Press, 2014, 201-205.

[63] Whitman, R. V. and Lambe, P. C., Effect of Boundary Conditions upon Centrifuge Experiments Using Ground Motion Simulation. Geotech. Test. J., 1986, Vol. 9(2), pp. $61-71$.

[64] Hushmand, B., Scott, R. F., and Crouse, C. B., Centrifuge Liquefaction Test in a Laminar Box. Geotechnique, 1988, Vol. 38(2), pp. 253-262.

[65] Dewoolkar, M. M., Ko. H. Y., Stadler, A. T., and Astaneh, S. M. F., A Substitute Pore Fluid for Seismic Centrifuge Modeling. ASTM Geotechnical Testing Journal, 1999, Vol. 22, No. 3, 196-210. 
[66] Ketcham, S. A., Ko, H.-Y. \& Sture, A., Performance of an Earthquake Motion Simulator for a Small Geotechnical Centrifuge. Proceedings: Centrifuge 91. Boulder, CO., 1991.

[67] Mason, H.B., Bray, J.D., Kutter, B.L., Wilson, D.W., and Choy, B.Y., Earthquake Motion Selection and Calibration for Use in a Geotechnical Centrifuge. 7th Int. Conf. on Physical Modeling in Geotechnics. Zurich, Switzerland, 2010.

[68] Seed, H.B. and Idriss I.M., Soil Moduli and Damping Factors for Dynamic Response Analyses. Rep. No. EERC70-10. Earthquake Eng. Res. Ctr., Univ. of California, Berkeley, Calif.. 1970.

[69] Hardin, B. O., The nature of stress-strain behavior of soils. Proceedings, Earthquake Engineering and Soil Dynamics, ASCE Pasadena, California, 1978, Vol. 1, pp. 3-89.

[70] Dobry, R., Borcherdt, R. D., Crouse, C. B., Idriss, I. M., Joyner, W. B., Martin, G. R., Power, M. S., Rinne, E. E., Seed, R. B., New Site Coefficients and Site Classification System Used in Recent Building Seismic Code Provisions. Earthquake Spectra, 2000, Vol. 16(1), pp. 41- 67.

[71] Roesset, J. M., Soil Amplification in Earthquakes. Numerical Methods in Geotechnical Engineering, C. S. Desai and J. T. Christian, eds., McGraw Hill, New York, 1977, Chapter 19, 639-682.

[72] Gibbs, J. F., Tinsley, J. C., and Joyner, W. B., Seismic Velocities and Geological Conditions at Twelve Sites Subjected to Strong Ground Motion in the 1994 Northridge California, Earthquake. U.S. Geological Survey Open-File Report 96-740, 1996, 103 pp. [73] Dong, Y., McCartney, J. S., Lu, N. Small-Strain Shear Modulus Model for Saturated and Unsaturated Soil. Go-Chicago 2016, Chicago, pp. 316-325.

[74] Menq, F. Y., Dynamic Properties of Sandy and Gravelly Soils. PhD Dissertation, the University of Texas at Austin, 2003.

[75] Lu, N., Godt, J. W., and Wu, D. T., A Closed Form Equation for Effective Stress in Unsaturated Soil. Water Resources Research, 2010, 46, W05515, 14pp.

[76] Arias, A., A measure of earthquake intensity. Seismic design for nuclear power plants. Hansen RJ, editor. Cambridge, MA. MIT Press; 1970.

[77] Zeghal, M., Elgamal, A. W., Tang, H. T., and Stepp, J. C. Lotung downhole array. II: Evaluation of soil nonlinear properties. Journal of Geotechnical Engineering, 1995, Vol. 4 No. 363, 363-378.

Table 1. Site classification (after NEHRP Provisions [21]) 


\begin{tabular}{|c|c|c|}
\hline$\frac{\text { NEHRP }}{\text { Category }}$ & $\underline{\text { Description }}$ & $\frac{\text { Time-weighted Average }}{\text { Shear Wave Velocity }}$ \\
\hline A & Hard rock & $>1500 \mathrm{~m} / \mathrm{s}$ \\
\hline B & Firm to hard rock & $760-1500 \mathrm{~m} / \mathrm{s}$ \\
\hline $\mathrm{C}$ & Dense soil, soft rock & $360-760 \mathrm{~m} / \mathrm{s}$ \\
\hline $\mathrm{D}$ & Stiff soil & $180-760 \mathrm{~m} / \mathrm{s}$ \\
\hline $\mathrm{E}$ & Soft clays & $<180 \mathrm{~m} / \mathrm{s}$ \\
\hline $\mathrm{F}$ & $\begin{array}{l}\text { Special study soils, e.g. liquefiable } \\
\text { soils, sensitive clays, organic soils, } \\
\text { soft clays }>36 \text { thick }\end{array}$ & \\
\hline
\end{tabular}


Table 2. Physical and hydraulic properties of F-75 Ottawa sand

\begin{tabular}{|c|c|}
\hline$\underline{\text { Parameter }}$ & $\underline{\text { Value }}$ \\
\hline Coefficient of curvature, $\mathrm{C}_{\mathrm{c}}$ & 1.71 \\
\hline Coefficient of uniformity, $\mathrm{C}_{\mathrm{u}}$ & 1.01 \\
\hline Specific gravity, $\mathrm{G}_{\mathrm{s}}$ & 2.65 \\
\hline $\mathrm{D}_{50}(\mathrm{~mm})$ & 0.182 \\
\hline Dry density limits, $\rho_{\mathrm{d}-\mathrm{min}}, \rho_{\mathrm{d}-\max }\left(\mathrm{kg} / \mathrm{m}^{3}\right)$ & 1469,1781 \\
\hline Void ratio limits, $\mathrm{e}_{\min }, \mathrm{e}_{\max }$ & $0.49,0.80$ \\
\hline Relative density, $\mathrm{D}_{\mathrm{r}}$ & 0.45 \\
\hline Friction angle (deg) & 40 \\
\hline Poisson's ratio, $v$ & 0.38 \\
\hline Saturated Hydraulic Conductivity, $\mathrm{k}_{\mathrm{s}}(\mathrm{cm} / \mathrm{s})$ & $6 \times 10^{-4}$ \\
\hline van Genuchten's a $\mathrm{v}_{\mathrm{V}}$ parameter for Drying Path $\left(\mathrm{kPa}^{-1}\right)$ & 0.25 \\
\hline van Genuchten's $\mathrm{N}_{\mathrm{vG}}$ parameter for Drying Path & 9 \\
\hline Residual volumetric water content for Drying Path,$\theta_{\mathrm{r}}$ & 0.07 \\
\hline Saturated volumetric water content for Drying Path , $\theta_{\mathrm{s}}$ & 0.392 \\
\hline van Genuchten's a $\mathrm{v}_{\mathrm{V}}$ parameter for Wetting Path $\left(\mathrm{kPa}^{-1}\right)$ & 0.7 \\
\hline van Genuchten's N $\mathrm{vG}_{\mathrm{v}}$ parameter for Wetting Path & 5 \\
\hline Residual volumetric water content for Wetting Path, $\theta_{\mathrm{r}}$ & 0.07 \\
\hline Saturated volumetric water content for Wetting Path, $\theta_{\mathrm{s}}$ & 0.322 \\
\hline
\end{tabular}




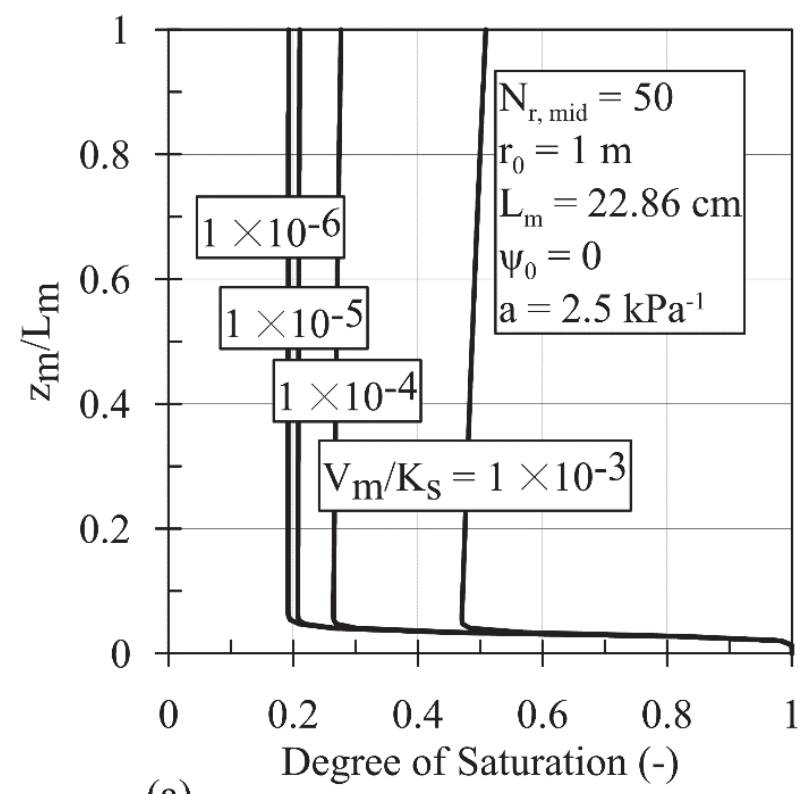

(a)

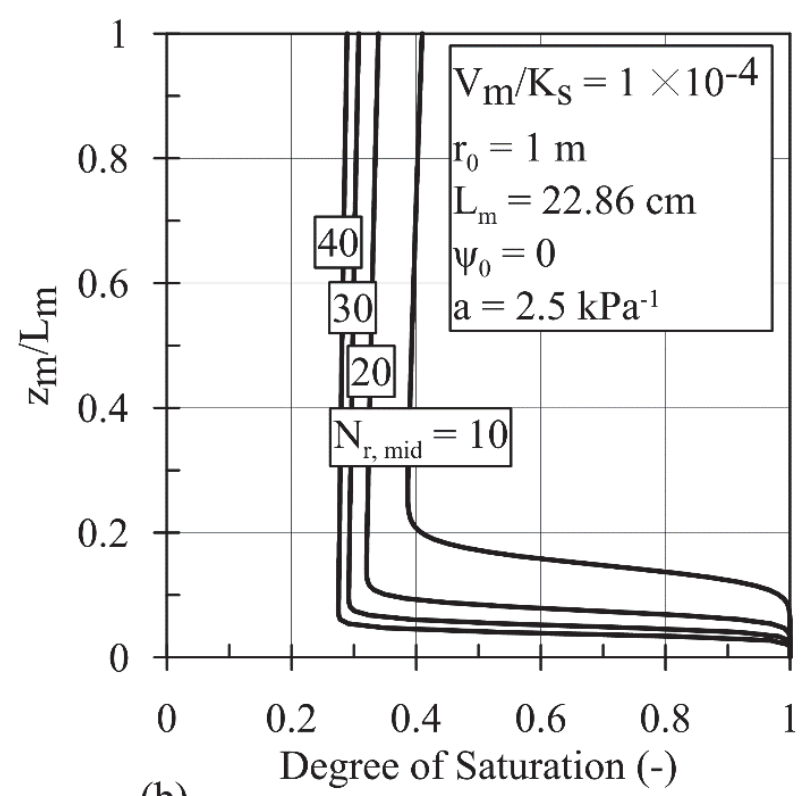

(b)

Figure 1. Analytical degree of saturation profiles during steady-state infiltration (after Dell'Avanzi et al. [59]): (a) for different discharge velocities; (b) for different glevels.

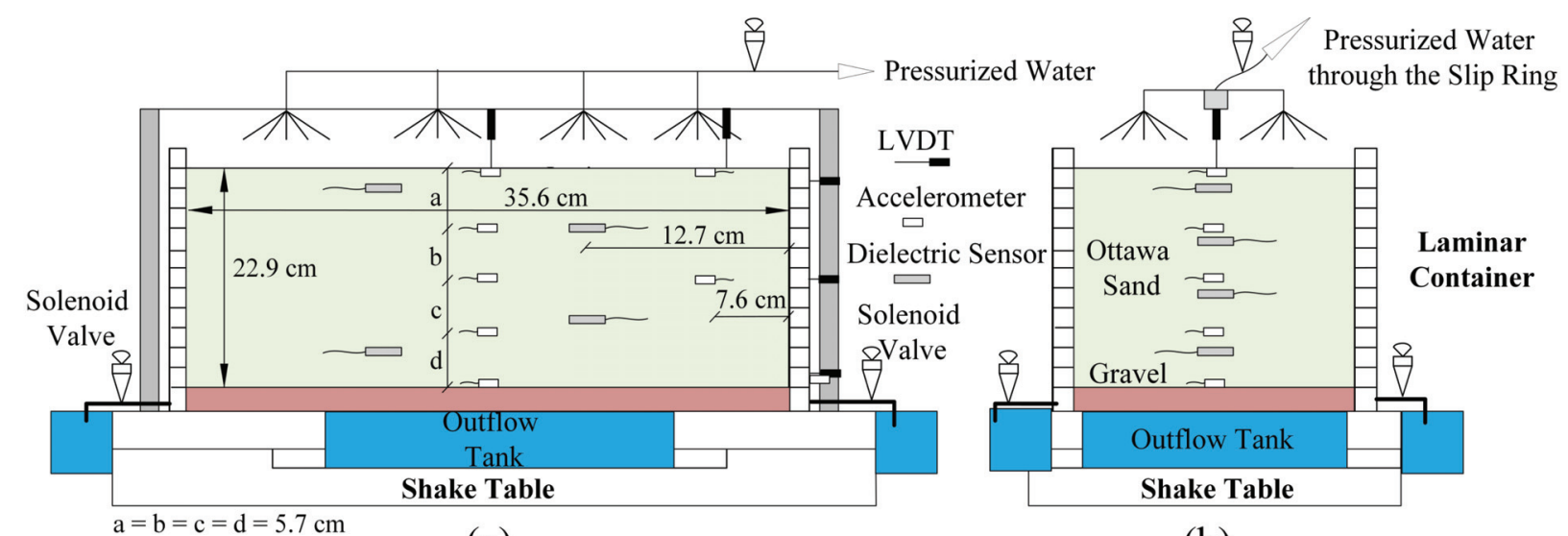

(a)

(b)

Figure 2. Instrumentation in the laminar container modified for steady-state infiltration:

(a) Side-view Schematic (b) Front-view Schematic. 


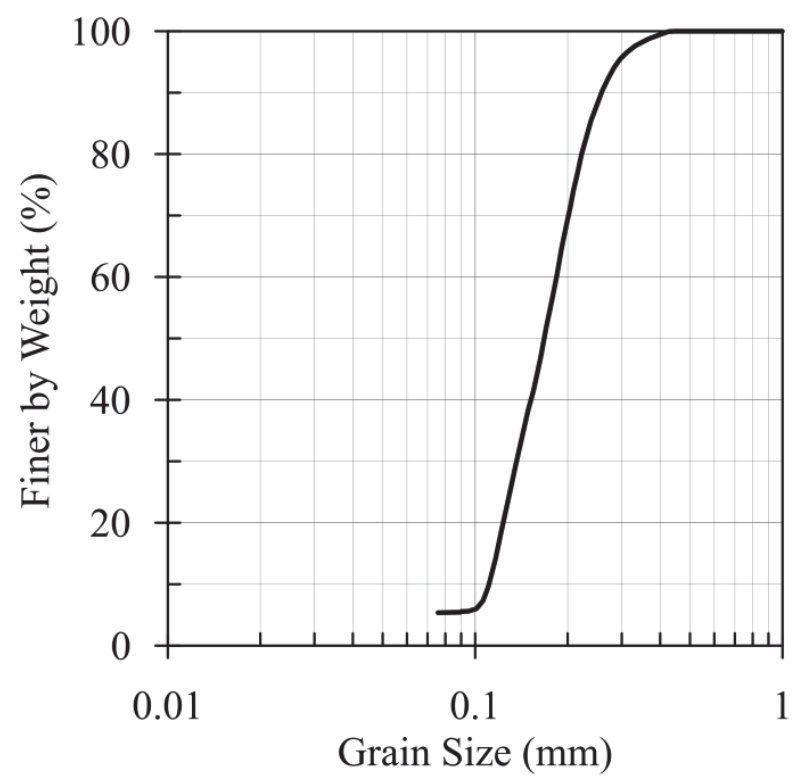

(a)

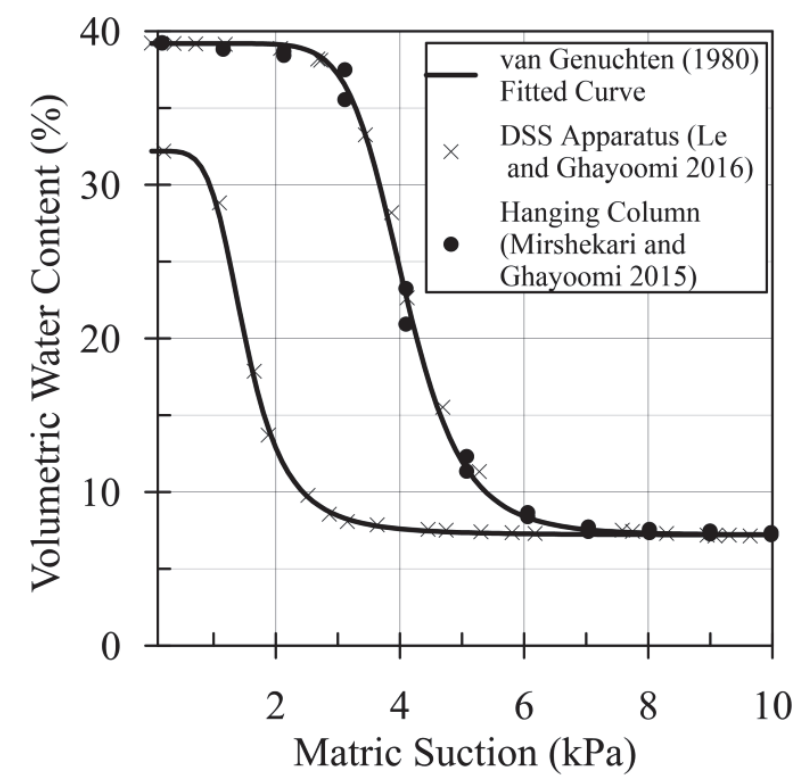

(b)

Figure 3. Properties of F-75 Ottawa sand: (a) Grain size distribution; (b) SWRC. 


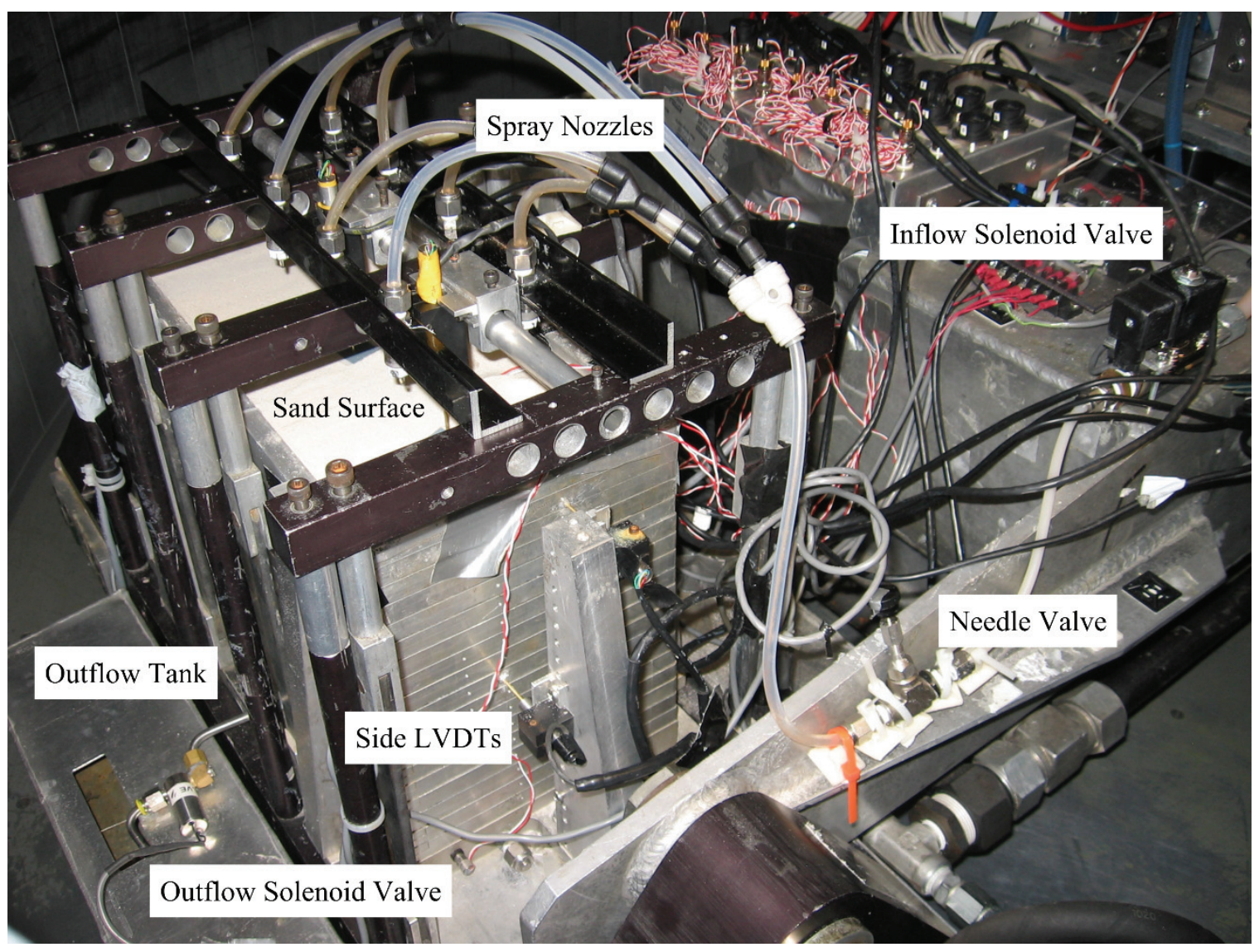

Figure 4. Fully assembled experimental setup.

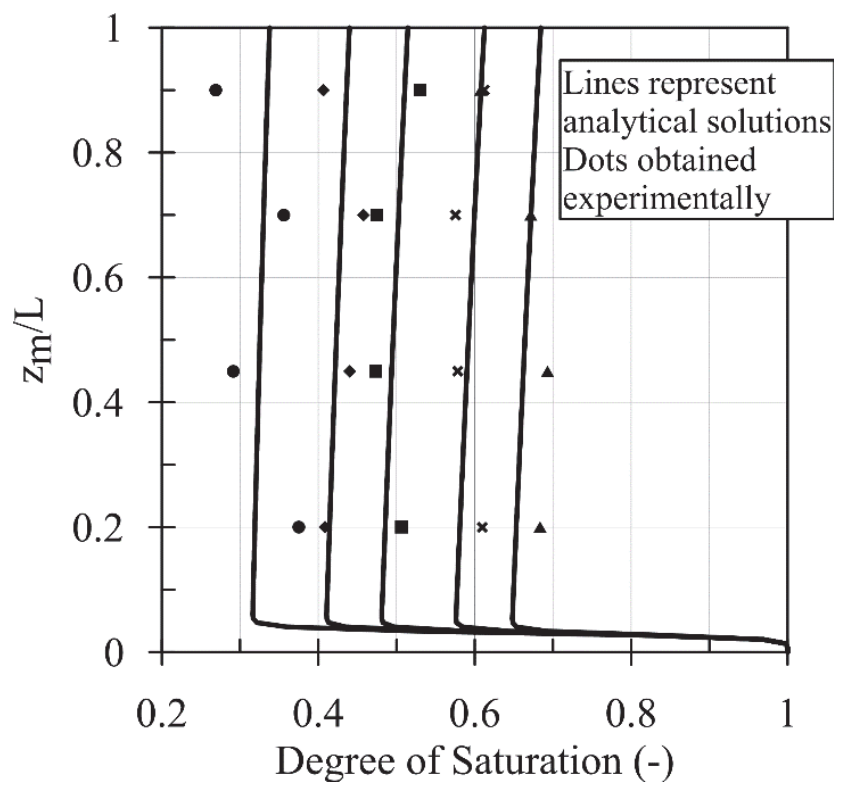

Figure 5. Experimentally developed profiles of degree of saturation along with the analytical solutions (after Dell'Avanzi et al. [59]). 

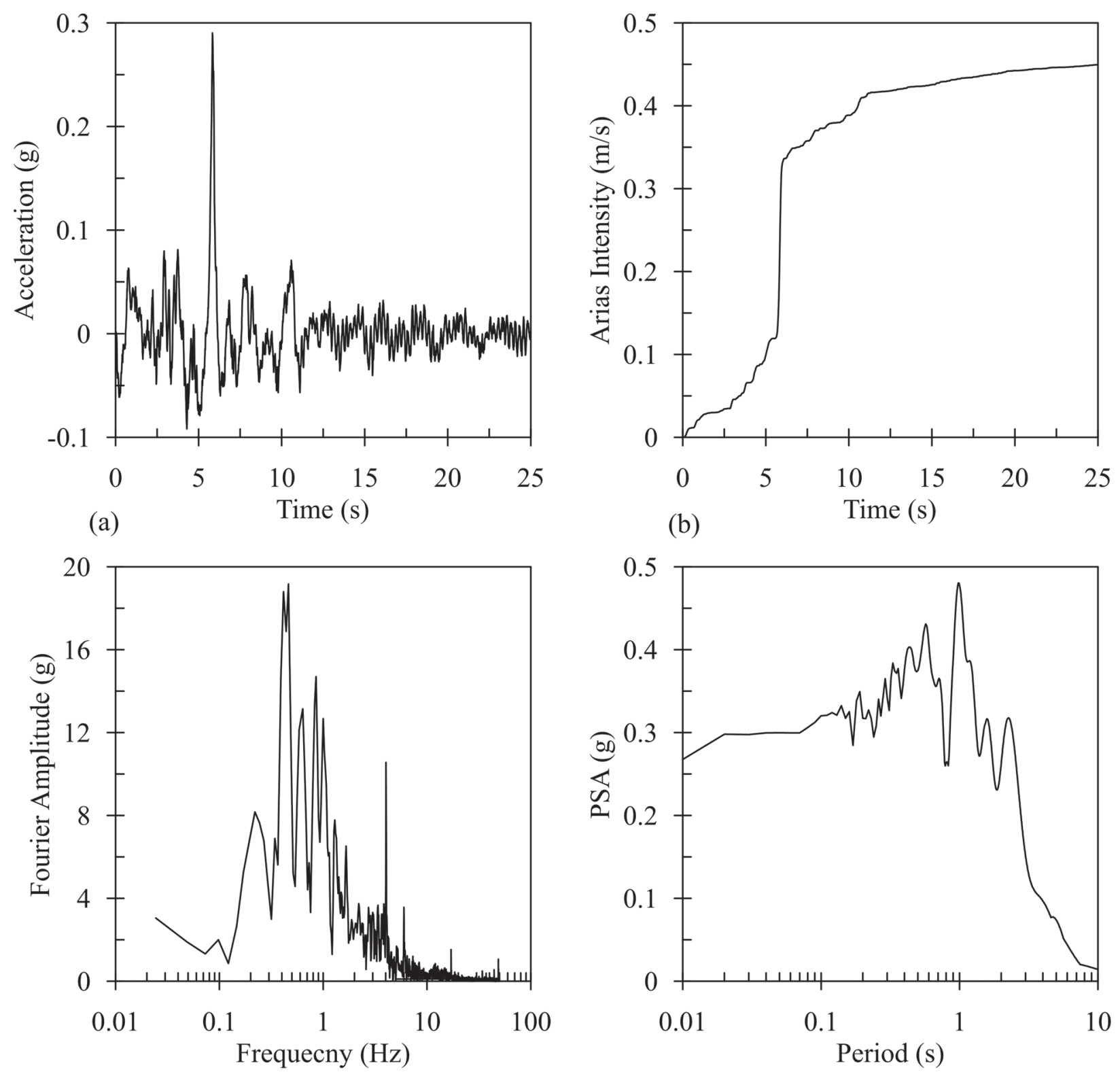

(c)

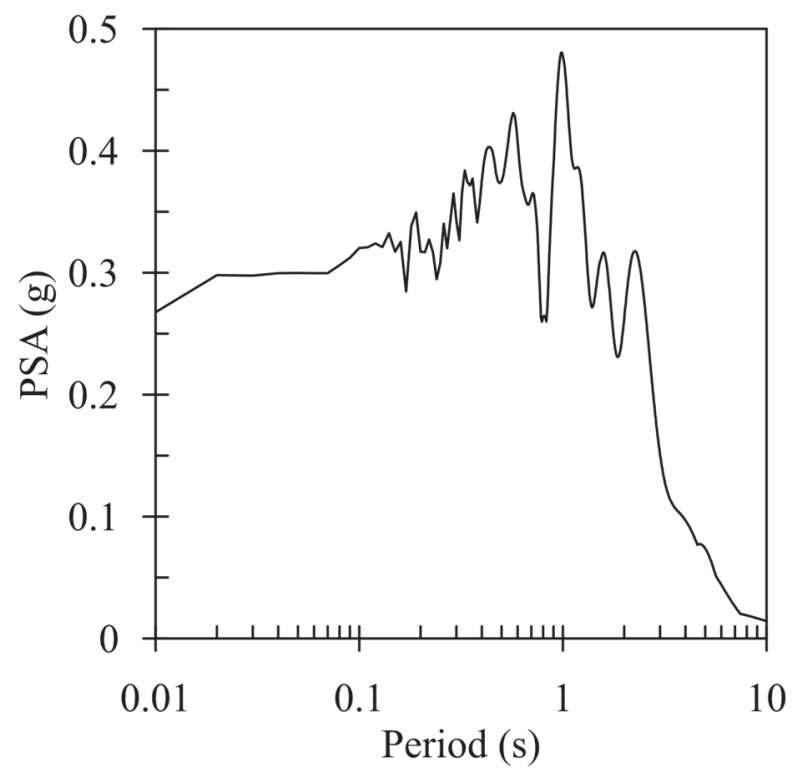

(d)

Figure 6. Applied scaled Northridge earthquake motion characteristics: (a) Acceleration time history; (b) Arias intensity; (c) Fourier amplitude; (d) 5\% damped spectral acceleration. 


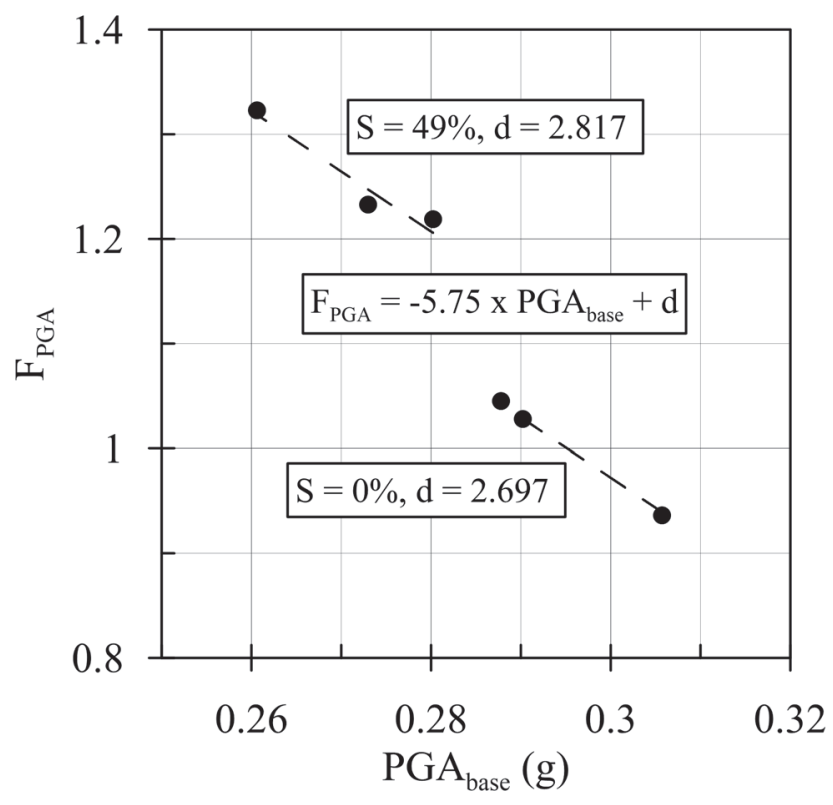

Figure 7. Correlation of PGA amplification factor ( $\left.F_{P G A}\right)$ and base peak ground acceleration (PGA base $_{\text {) }}$. 

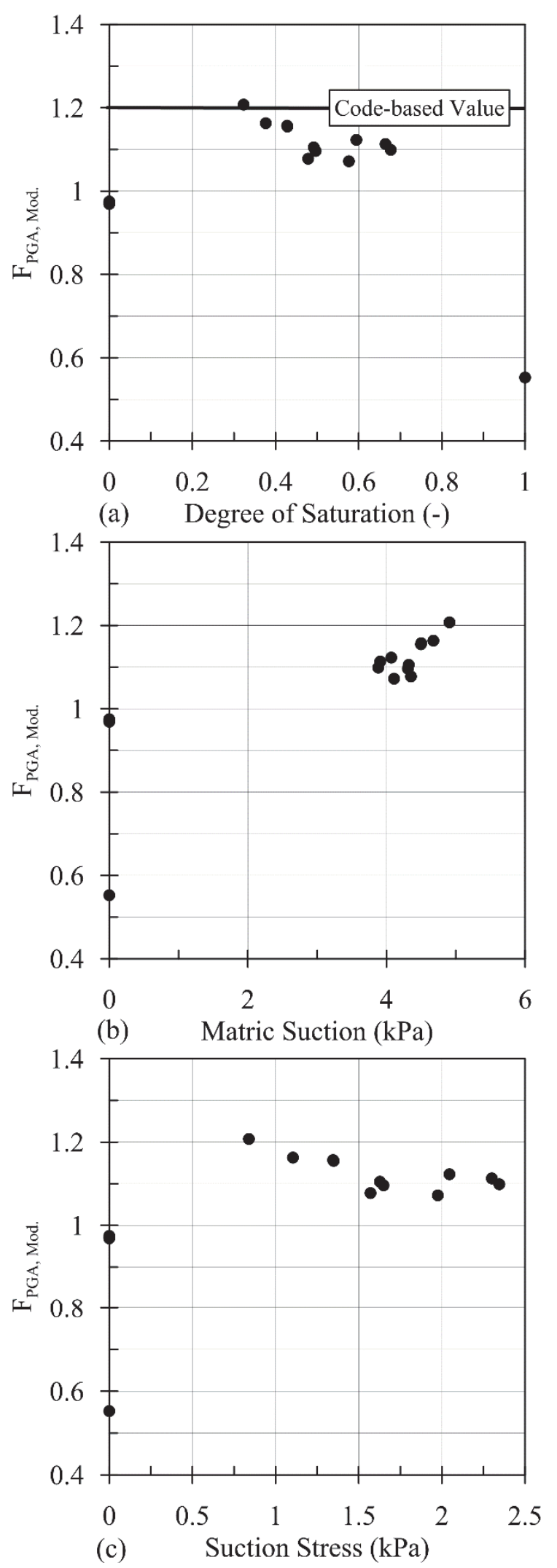

Figure 8. PGA amplification factor ( $\mathrm{FPGA}_{\mathrm{PA}}$ ) for sand layers with different (a) degrees of saturation; (b) matric suction; and (c) suction stress. 


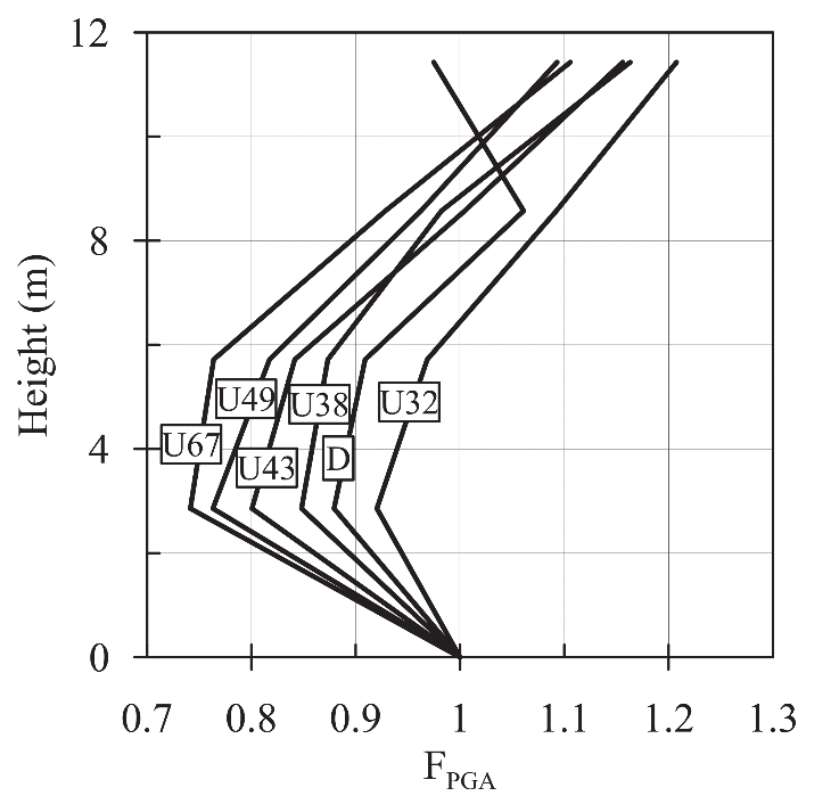

Figure 9. Profiles of PGA amplification factors ( $\left.F_{P G A}\right)$ for sand layers with different degrees of saturation.

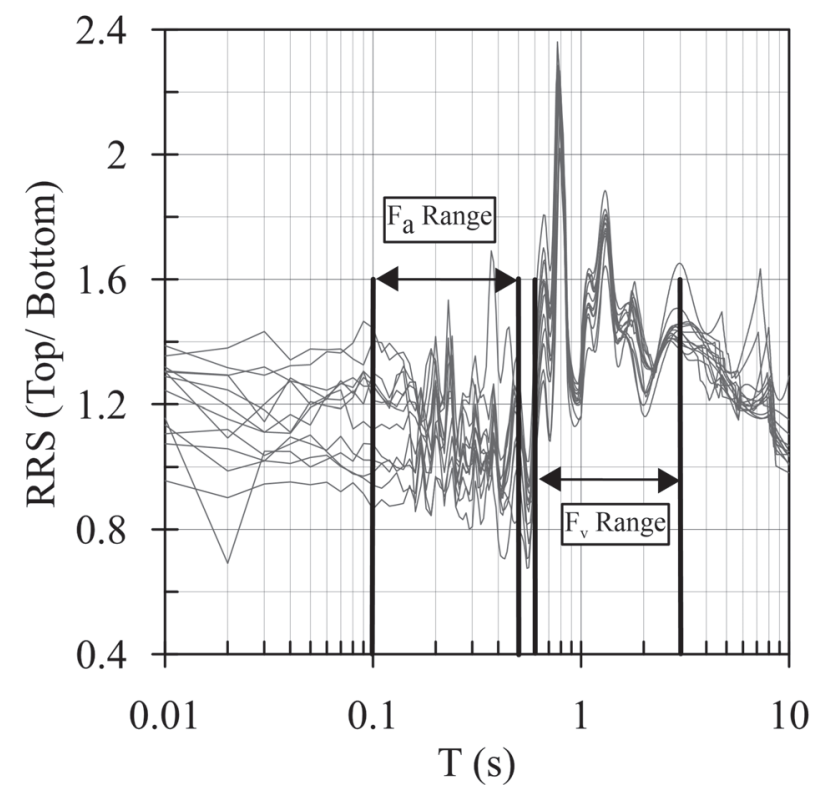

Figure 10. Period range selection procedure for low- and mid-period amplification factors. 

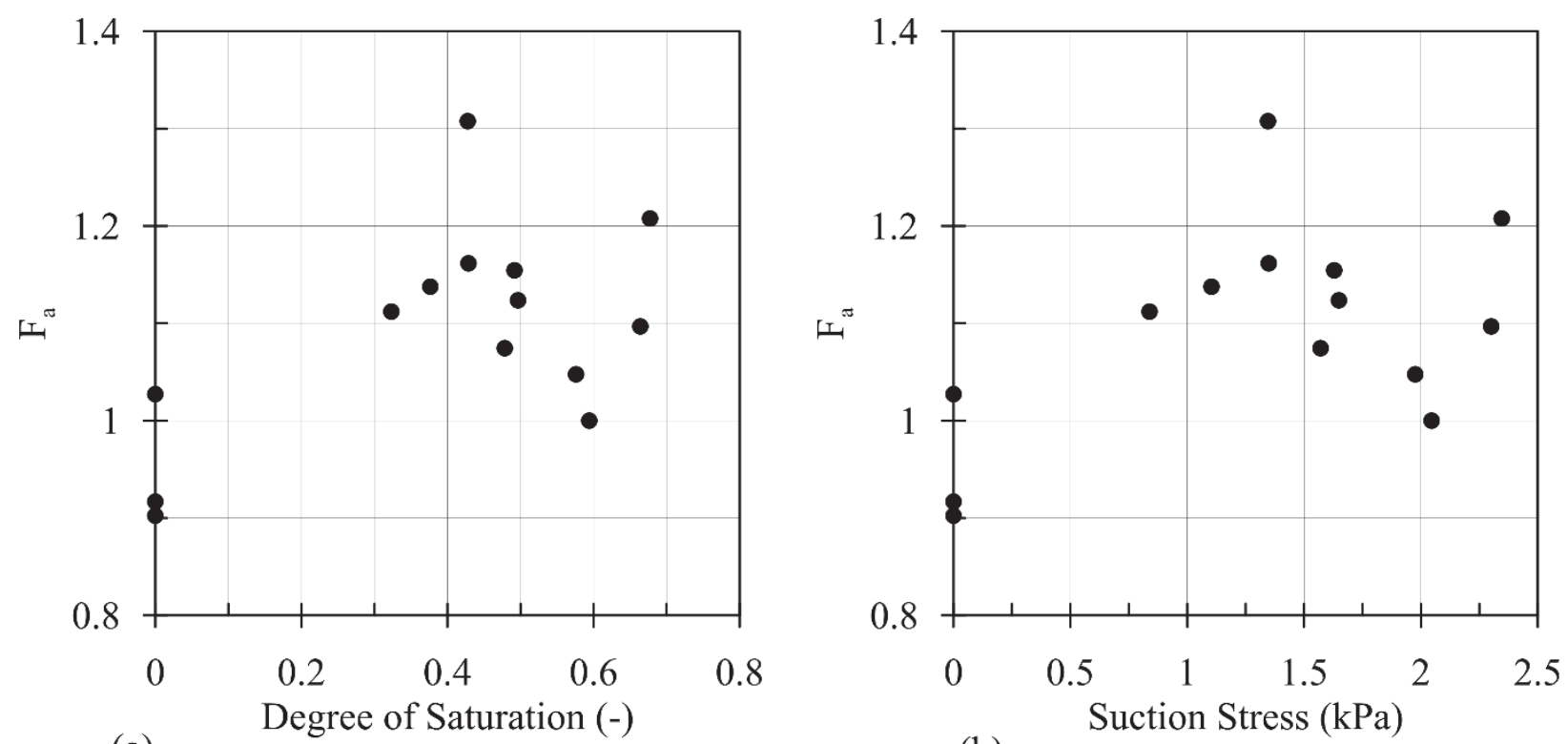

(a)

(b)

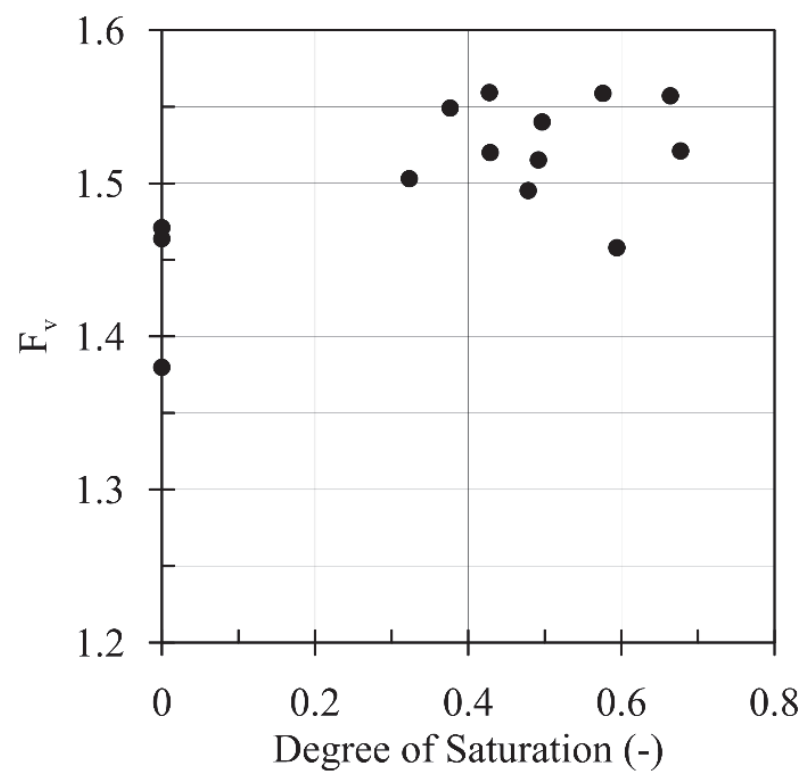

(c)

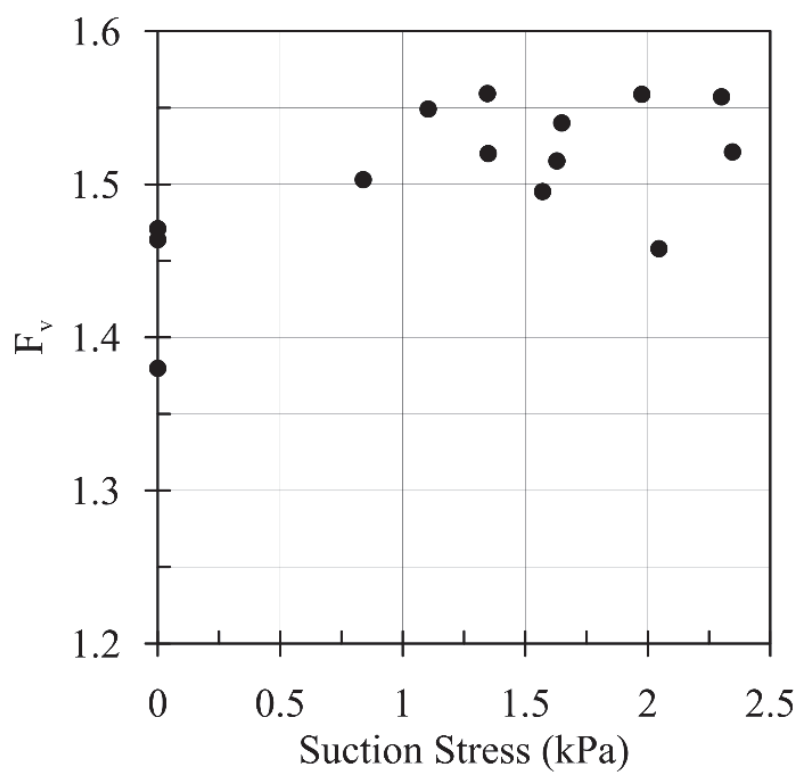

(d)

Figure 11. Low-period amplification factors $\left(F_{a}\right)$ for different: (a) degrees of saturation; and $(b)$ suction stress. Mid-period amplification factors $\left(F_{v}\right)$ for different: (c) degrees of saturation; and (d) suction stress. 


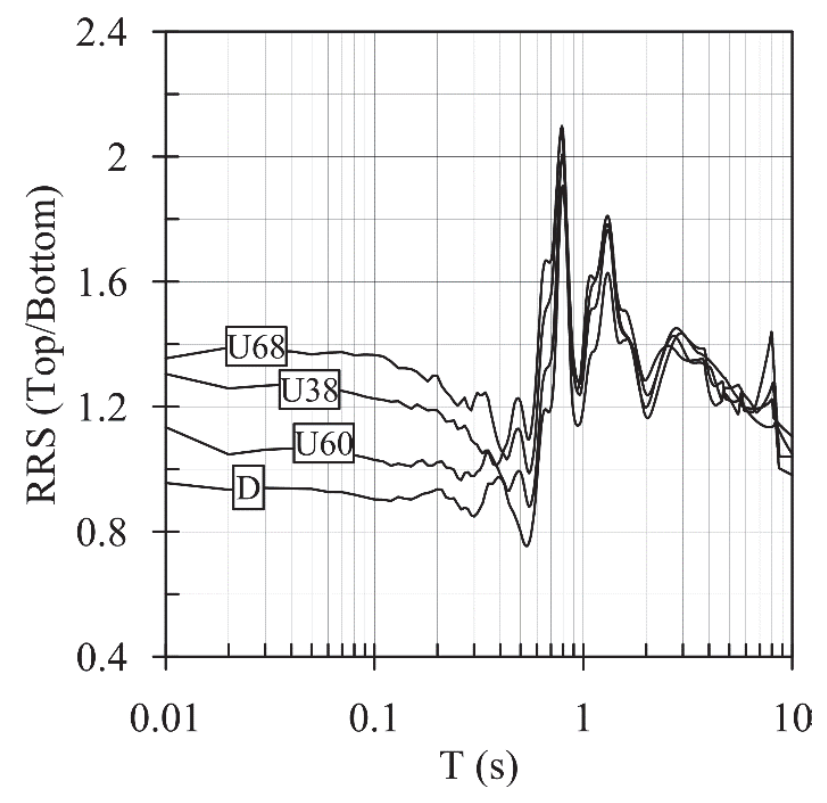

Figure 12. Ratio of Reponses Spectra (RSS) for selected tests for sand layers with different degrees of saturation.

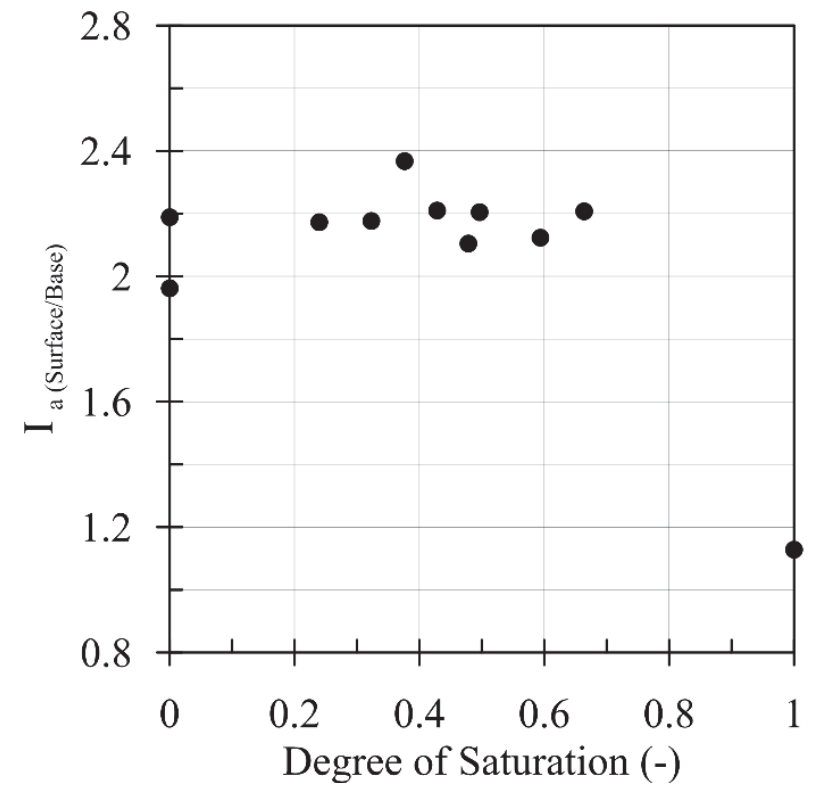

Figure 13. Surface-to-base ratio of Arias intensity for sand layers with different degrees of saturation. 


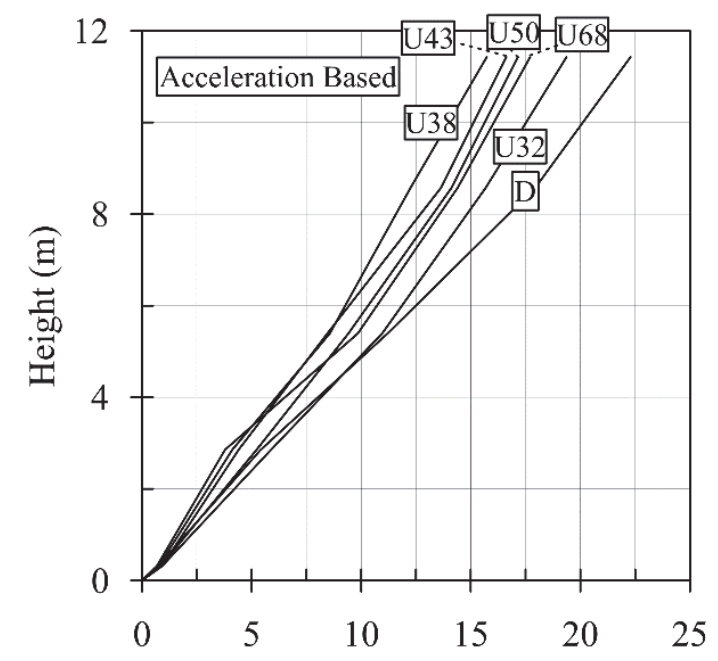

(a) Lateral Deformation $(\mathrm{cm})$
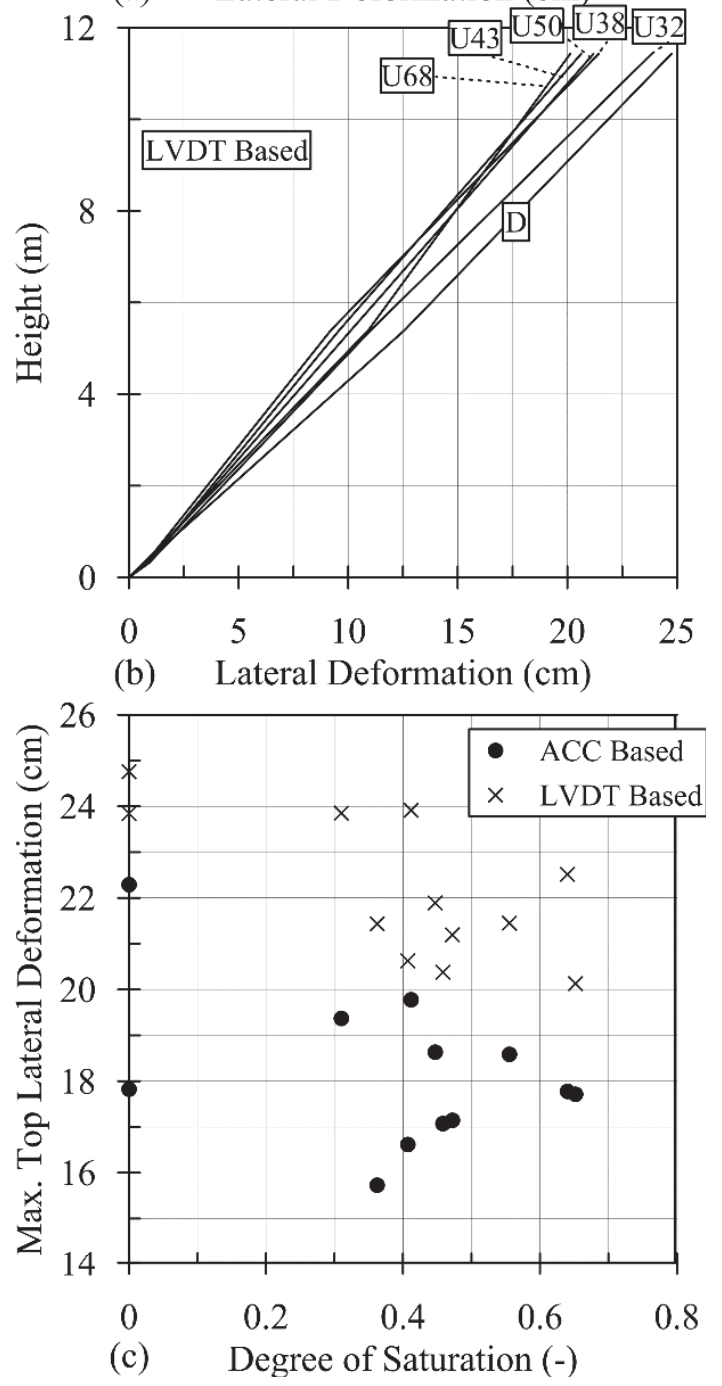

Figure 14. Maximum lateral deformation profiles for selected tests with different degrees of saturation based on (a) LVDT measurements; and (b) accelerometer 
measurements. (c) Maximum surface deformation of sand layers with different degrees of saturation.

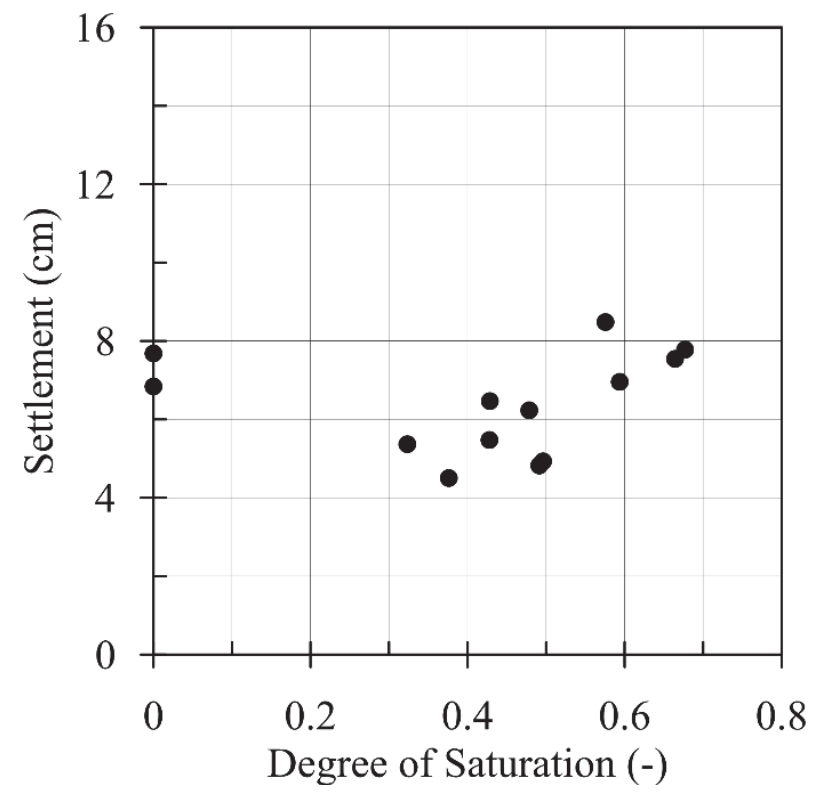

Figure 15. Seismic surface settlement of sand layers with different degrees of saturation. 